\title{
Targeted deletion of a cis-regulatory region reveals differential gene dosage requirements for $P d x 1$ in foregut organ differentiation and pancreas formation
}

\author{
Yoshio Fujitani, ${ }_{1}^{1}$ Shuko Fujitani, ${ }^{1}$ Daniel F. Boyer, ${ }^{1}$ Maureen Gannon, ${ }^{2,3}$ Yoshiya Kawaguchi, ${ }^{4}$ \\ Michael Ray, ${ }^{1}$ Masakazu Shiota, ${ }^{2}$ Roland W. Stein, ${ }^{1,3}$ Mark A. Magnuson, ${ }^{1,3}$ and \\ Christopher V.E. Wright ${ }^{1,5}$ \\ ${ }^{1}$ Vanderbilt Program in Developmental Biology and Department of Cell and Developmental Biology, ${ }^{2}$ Department of \\ Medicine, and ${ }^{3}$ Department of Molecular Physiology and Biophysics, Vanderbilt University School of Medicine, Nashville, \\ Tennessee 37232-2175, USA; ${ }^{4}$ Department of Surgery and Surgical Basic Science, Kyoto University Graduate School of \\ Medicine, Kyoto 606-8507, Japan
}

$P d x 1$ (IPF-1 in humans, which is altered in MODY-4) is essential for pancreas development and mature $\beta$-cell function. Pdx1 is expressed dynamically within the developing foregut, but how its expression characteristics are linked to the various steps of organ specification, differentiation, and function is unknown. Deletion of a conserved enhancer region (Area I-II-III) from Pdx1 produced a hypomorphic allele $\left(P d x 1^{\Delta I-I I-I I I}\right)$ with altered timing and level of expression, which was studied in combination with wild-type and protein-null alleles. Lineage labeling in homozygous Area I-II-III deletion mutants $\left(P d x 1^{\Delta I-I I-I I I / \Delta I-I I-I I I}\right)$ revealed lack of ventral pancreatic bud specification and early-onset hypoplasia in the dorsal bud. Acinar tissue formed in the hypoplastic dorsal bud, but endocrine maturation was greatly impaired. While Pdx1-/- (protein-null) mice have nonpancreatic abnormalities (e.g., distorted pylorus, absent Brunner's glands), these structures formed normally in $P d x 1^{\Delta I-I I-I I I / \Delta I-I I-I I I}$ and $P d x 1^{\Delta I-I I-I I I /}$ mice. Surprisingly, heterozygous $\left(P d x 1^{+/ \Delta I-I I-I I I}\right)$ mice had abnormal islets and a more severe prediabetic condition than $P d x 1^{+/-}$mice. These findings provide in vivo evidence of the differential requirements for the level of $P d x 1$ gene activity in the specification and differentiation of the various organs of the posterior foregut, as well as in pancreas and gut endocrine cell differentiation.

[Keywords: Organogenesis; pancreatic $\beta$ cells; Pdx1; MODY; Enhancer; cis-element; foregut differentiation]

Supplemental material is available at http://www.genesdev.org.

Received July 28, 2005; revised version accepted November 30, 2005.

Studies in several vertebrate species have started to define conserved developmental pathways controlled by extrinsic and intrinsic factors that are essential for the development of the endocrine and exocrine pancreas (Kim and Hebrok 2001; Wilson et al. 2003; Jensen 2004). It is generally accepted that signals from mesodermal tissues control the early stage of pancreas development. Dorsal bud outgrowth depends on inductive signals from the nearby notochord (Kim et al. 1997; Hebrok et al. 1998), and its subsequent expansion and differentiation require signals from embryonic blood vessel cells (Lammert et al. 2001; Yoshitomi and Zaret 2004) and other signaling pathways, including Activin, FGFs, and Notch (Kim and Hebrok 2001; Wilson et al. 2003; Jensen 2004).

${ }^{5}$ Corresponding author.

E-MAIL chris.wright@vanderbilt.edu; FAX (615) 322-1917.

Article and publication are at http://www.genesdev.org/cgi/doi/10.1101/ gad.1360106.
These signals affect the expression of transcription factors that execute the pancreatic developmental program.

Among the transcription factors identified as essential for proper pancreas differentiation, the homeodomain protein Pdx1 (also known as IPF-1, STF-1, or IDX-1) (Wright et al. 1989; Leonard et al. 1993; Ohlsson et al. 1993; Miller et al. 1994) is both expressed in precursors of the endocrine and exocrine compartments of the pancreas (Gu et al. 2002), and is essential for their development and maintenance, especially the insulin-producing $\beta$ cells (Jonsson et al. 1994; Offield et al. 1996; Ahlgren et al. 1998; Holland et al. 2002). In addition to pancreatic agenesis, $P d \times 1^{-1-}$ mouse mutants have defects throughout the posterior foregut region, including distorted gastro-duodenal junction, loss of Brunner's glands, and deficiency of enteroendocrine differentiation in the stomach and duodenum (Larsson et al. 1996; Offield et al. 1996; Jepeal et al. 2005). Loss of IPF-1 function also results in pancreatic agenesis in humans (Stoffers et al. 1997). 
In mature $\beta$ cells, $P d x 1$ transactivates the Insulin gene and other genes involved in glucose sensing and metabolism, such as Glut2 and Glucokinase (Waeber et al. 1996; Watada et al. 1996). $P d \times 1^{+/-}$mice are glucose intolerant, indicating that gene dosage for $P d x 1 / I P F-1$ is crucial for normal glucose homeostasis (Ahlgren et al. 1998; Dutta et al. 1998; Brissova et al. 2002; Johnson et al. 2003). These findings are concordant with the prior discovery that humans heterozygous for an inactivating mutation of IPF-1 are at elevated risk for adult-onset type II diabetes and are linked to a dominant heritable condition, maturity onset diabetes of the young type 4 (MODY4) (Stoffers et al. 1997, 1998).

The regulatory mechanisms that orchestrate the complex developmental transitions involved in cellular differentiation and function during pancreatic organogenesis are far from elucidated. Normal endocrine pancreas development and function depends on a highly integrated transcription-factor network, and even subtle abnormalities in islet tissue caused by heterozygosity or reduced gene dosage of MODY susceptibility genes can substantially predispose toward severe diabetes in humans (Bell and Polonsky 2001). Recent promoter analyses of genes involved in islet differentiation and function suggest complex genetic interactions among these factors (Shih et al. 2002; Servitja and Ferrer 2004). Most of this evidence, however, is inferred from in vitro studies using immortalized $\beta$-cell lines or other cells such as ES cells, which are perhaps of limited relevance to normal ontogeny and organogenesis.

As one key entry point into understanding the operation of these gene regulatory networks in vivo, we have examined the cis- and trans-regulation of $P d x 1$. Alignment of the mouse and human $P d x 1$ gene sequences revealed three phylogenetically conserved regions referred to collectively as Area I-II-III (Gerrish et al. 2000), which are also characterized as $\mathrm{PH}-1, \mathrm{PH}-2$, and $\mathrm{PH}-3$ in human (Melloul et al. 2002). The Area I-II-III region harbors binding sites for MODY transcription factors such as HNF-1 $\alpha$ and Pdx1 itself (Marshak et al. 2000; Gerrish et al. 2001), as well as other endodermal and islet-enriched transcriptional regulators, including Foxa2/HNF3 $\beta$ (Gerrish et al. 2000; Ben-Shushan et al. 2001), Pax6 (Samaras et al. 2002), Maf/RIPE3b1 (Samaras et al. 2003), and HNF-6/OC-1 (Jacquemin et al. 2003). We have reported on sufficiency tests in transgenic mice and cultured cell lines that identified islet-specific (PstI-BstEII fragment: containing Area I-II) and $\beta$-cell-specific (XhoI-BglII fragment: containing Area III and an adjacent 3' region) cisregulatory regions that overlap with Area I-II-III, suggesting that Area I-II-III functions specifically in differentiation and maintenance of pancreatic islets $(\mathrm{Wu}$ et al. 1997; Gerrish et al. 2000, 2001; Gannon et al. 2001; Samaras et al. 2002). A slightly more distal Area IV, which can act in vitro to drive $\beta$-cell-selective and glucocorticoid-regulated transcription of rat $P d x 1$ (STF-1) (Sharma et al. 1997), may also potentiate Area I/II-mediated activity in $\beta$ cells (Gerrish et al. 2004).

Here we demonstrate that removal of conserved sequences from the endogenous $P d x 1$ locus results in a decreased level and abnormal spatiotemporal expression of $\mathrm{Pdx} 1$ protein. Our studies overcome a main caveat of transgenic studies, which do not elucidate the function of transcriptional elements in a native chromosomal context. This study lays the foundation for further in vivo dissection of the networks that control pancreas organogenesis via the direct and precise manipulation of $P d \times 1$ and its trans-regulatory genes.

\section{Results}

Targeting of the Pdx1 locus with an Area I-II-III floxed sequence

Gene targeting in ES cells was used to delete Area I-II-III from the endogenous $P d x 1$ locus (Fig. 1). The targeting vector contained the $1.2-\mathrm{kb}$ Area I-II-III flanked by loxP sites and FRT-flanked PGKneopA $\left(\mathrm{neo}^{-}\right)$cassette in the $3^{\prime}$ adjacent region. Vector electroporation into ES cells, positive-negative selection, and Southern blot analysis (data not shown) gave rise to frt-neo ${ }^{r}$ heterozygous ES cell clones. These cells were injected into C57BL/6 blastocysts, and chimeric mutant mice derived. The neo ${ }^{r}$ cassette was excised in vivo by crossing chimeras to mice expressing the Flpe recombinase (ACTB:FLPe), leading to $P d x 1^{\text {floxI-II-III/+ }}$ offspring.

After neo ${ }^{r}$ cassette removal, the remaining FRT site and adjacent $\operatorname{lox} P$ site accounted for $\sim 200$ base pairs (bp) of exogenous bystander sequence in the $P d x 1^{\text {floxI-II-III }}$ allele. We ascertained that this extra sequence does not disrupt the function of the floxed allele by examining litters derived from mating $P d x 1^{\text {floxI-II-III/+ }}$ mice to $P d \times 1^{+/-}$mice (Offield et al. 1996). All genotypes arose at the expected Mendelian frequency. No significant differences in appearance or body weight were observed at birth or 4 wk of age between $P d x 1^{\text {floxI-II-III/- }}$ mice and their controls: $P d x 1^{\text {floxI-II-III/+}}, P d x 1^{+/-}$, and $P d x 1^{+/+}$(data not shown). Immunohistochemical analyses revealed that $P d \times 1^{f l o x I-I I-I I I /-}$ mice have normal islets with all four major endocrine cell types $(\alpha, \beta, \delta$, and $\mathrm{PP}$; producing glucagon, insulin, somastatin, or pancreatic polypeptide, respectively) arranged indistinguishably from those in $P d \times 1^{+/-}$mice (data not shown). Pdx $1^{\text {floxI-II-III/floxI-II-III }}$ mice also showed normal islet morphology and architecture. Intraperitoneal glucose tolerance test (IP-GTT) demonstrated that glucose clearance in $P d x 1^{f l o x I-I I-I I I /+}$ mice was comparable to wild-type mice (data not shown). We therefore conclude that the floxI-II-III allele is functionally equivalent to the wild-type allele.

\section{Pancreatic agenesis in $\mathrm{Pdx} 1^{\Delta \mathrm{I}-\mathrm{II}-\mathrm{III} /-}$ mutants}

Germline deletion of Area I-II-III was accomplished by crossing $P d x 1^{\text {floxI-II-III/+ }}$ mice to EIIaCre transgenic mice. Because EIIaCre produces a mosaic pattern of recombination by paternal transmission, candidate $\mathrm{F} 1 \mathrm{mu}-$ tants were screened by Southern blot and PCR /data not shown) to confirm deletion of Area I-II-III, yielding the $P d \times 1^{\Delta I-I I-I I I}$ allele (Fig. 1). $P d x 1^{\Delta I-I I-I I I /+}$ and $P d x 1^{+/-}$mice were mated to generate $P d \times 1^{\Delta I-I I-I I I /-}$ progeny. Neonatal $P d \times 1^{\Delta I-I I-I I I /-}$ mice were outwardly indistinguishable 


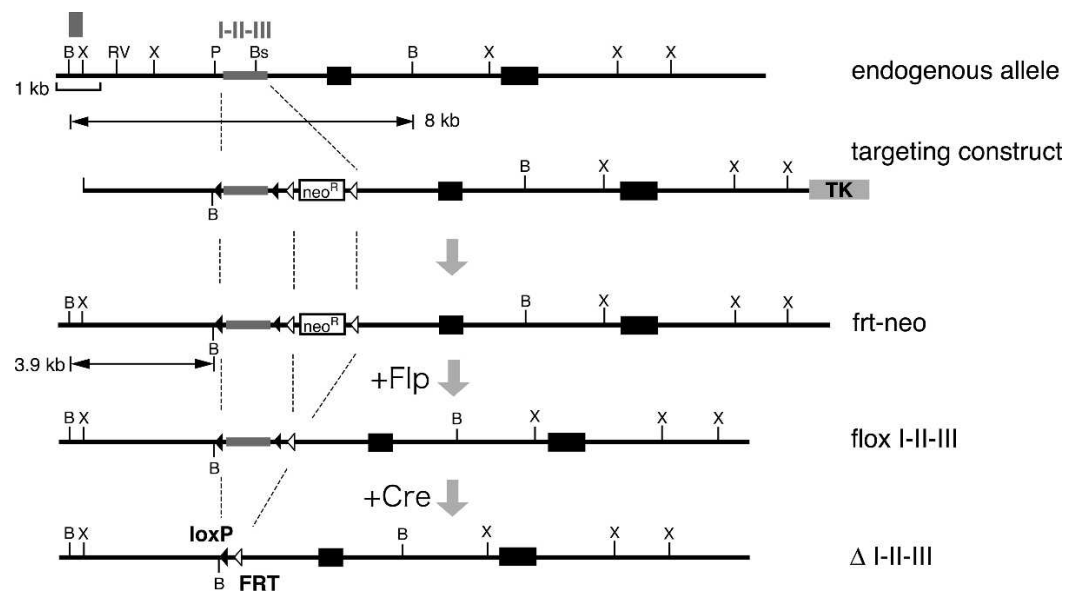

Figure 1. Strategy for deleting Area I-II-III within Pdx1. (Top) Pdx1 genomic structure. Area I-II-III lies $\sim 2 \mathrm{~kb} 5^{\prime}$ of the transcription start site. Homologous recombination with the targeting vector generated the frt-neo allele; Flp deletion created the flox I-II-III allele; subsequent Cre deletion led to the $\Delta$ I-II-III allele. (Black boxes) Exons; (gray box) B-X external probe for Southern blot analysis (diagnostic band lengths pre/post-recombination indicated). $\left(\right.$ neo $\left.^{\mathrm{R}}\right)$ Neomycin resistance cassette; (TK) thymidine kinase cassette. Black and white arrowheads indicate LoxP and FRT sites, respectively. (B) BamHI; (Bs) BstEII; (P) PstI; (RV) EcoRV; (X) XbaI. from $P d x 1^{+/+}$or $P d x 1^{+/-}$littermates. By postnatal day 2 (P2), however, $P d x 1^{\Delta I-I I-I I I /-}$ animals showed growth retardation and dehydration. Most $P d \times 1^{\Delta I-I I-I I I /-}$ pups died by $\mathrm{P} 9$, and none survived past $17 \mathrm{~d}$. Internal examination of P1 $P d x 1^{\Delta I-I I-I I I /-}$ pups revealed that the liver, gall bladder, spleen, and stomach were present and grossly normal. Also, the common bile duct was of similar diameter and length to that of wild-type littermates /data not shown). In all $P d \times 1^{\Delta I-I I-I I I /-}$ pups, the pancreas was replaced by a small rudiment protruding from the duodenal wall representing a stunted dorsal pancreatic outgrowth (see below). The dorsal outgrowth contained numerous small clusters of glucagon-producing cells at the tips of a ductular tree that displayed limited branching (Fig. 2I). No other endocrine hormones (insulin, somatostatin, PP), nor exocrine markers (e.g., amylase), were detected in the dorsal rudiment at birth, and Pdx1 protein was not detected in its epithelium at this stage (data not shown). Comparison of several animals of each genotype showed that the block to pancreas development in $P d \times 1^{\Delta I-I I-I I I /-}$ mice was indistinguishable from that in homozygous protein-null mice (Fig. 2H; Jonsson et al. 1994; Offield et al. 1996).

The early failure of ventral pancreatic bud formation was confirmed by using the $P d x 1^{\text {laczko }}$ allele (Offield et al. 1996), in which $P d x 1$ exon 2 is replaced by nucleartargeted $\beta$-galactosidase, to analyze the ontogeny of pancreas malformation in $P d \times 1^{\Delta I-I I-I I I /-}$ embryos. As previously reported (Offield et al. 1996), in $P d x 1$ heterozygous embryonic day 12.0 (E12.0) embryos $\left(P d x 1^{+/ l a c Z k o}\right), \beta$-galactosidase labels the endogenous $P d x 1$ expression domain, including the dorsal and ventral pancreatic buds, caudal stomach, rostral duodenum, and common bile duct (Fig. 2M). In $P d \times 1^{\Delta I-I I-I I I / l a c Z k o}$ mutants, the dorsal pancreatic bud was markedly smaller, with no sign of branching morphogenesis at this stage; a separate ventral pancreatic bud was not present (Fig. 2N).

$\mathrm{Pdx}^{\Delta \mathrm{I}-\mathrm{II}-\mathrm{III} / \Delta \mathrm{I}-\mathrm{II}-\mathrm{III}}$ animals show dorsal pancreas hypoplasia and loss of ventral pancreas

Intercrossing of $P d \times 1^{\Delta I-I I-I I I /+}$ mice generated $P d \times 1^{\Delta I-I I-I I I / \Delta I-I I-I I I}$ mice. The $P d \times 1^{\Delta I-I I-I I I / \Delta I-I I-I I I}$ pups lived at least $7 \mathrm{~d}$, but none survived beyond weaning $(n=17)$. While the dorsal pancreas of $P d x 1^{\Delta I-I I-I I I / \Delta I-I I-I I I}$ mice was hypoplastic (Fig. 3A,B), it developed substantially more than that of $P d x 1^{\Delta I-I I-I I I /-}$ mutants (Fig. 2C). Proximal to the duodenum, the pancreatic remnant contained a relatively expansive region of zymogen granuleladen acinar cells connected by a well-formed ductal network (Fig. 4C,D). Pancreatic endocrine cell differentiation in this zone was highly defective, with no well-differentiated islets observed (Fig. 4E-J). While glucagon-producing cells were abundant, they were less clustered than in wildtype tissue and did not surround a core of insulin-producing cells. All four major endocrine cell types $(\alpha, \beta, \delta$, and $\mathrm{PP}$ ) were detected, but only as small cell clusters, or single cells tightly apposed to ductal structures (arrows in Fig. $4 \mathrm{~F}, \mathrm{H}, \mathrm{J})$. The number of insulin-producing cells was dramatically decreased in $P d \times 1^{\Delta I-I I-I I I / \Delta I-I I-I I I}$ mutants (Fig. $4 \mathrm{G}, \mathrm{H})$, and these cells had a uniformly much lower insulin level. The portion of the dorsal pancreatic remnant distal to the duodenum (bracket in Fig. 3B) developed as a cyst-like structure lined by a simple cuboidal epithelium (Fig. 4B); no pancreatic endocrine or acinar markers were detected in or near it. The cystic epithelium produced cytokeratins typical of pancreatic ductal epithelium and lacked expression of Nkx6.1, a marker of the early, progenitor-stage pancreatic epithelium (data not shown). These findings provide evidence for regional (distal vs. proximal) differences in the differentiation program of the dorsal pancreatic bud as related to the gene dosage or spatial and temporal expression characteristics of the $P d \times 1^{\Delta I-I I-I I I}$ allele.

To gain insight into the etiology of pancreatic hypoplasia in $P d \times 1^{\Delta I-I I-I I I / \Delta I-I I-I I I}$ mice, we investigated embryonic stages. Analysis at E12.0 revealed progressive pancreas-specific reduction in $\mathrm{Pdx} 1$ protein immunoreactivity in the $P d \times 1^{\Delta I-I I-I I I / \Delta I-I I-I I I}$ and $P d \times 1^{\Delta I-I I-I I I /-}$ mutants (cf. signal in caudal stomach vs. dorsal pancreas; Fig. 5A-C). The relative signal intensities were consistent in careful side-by-side processing of several serial sections of the pancreatic region across three embryos of each genotype. Examination of gut-proximal dorsal pancreatic tissue at E16.5 (Fig. 5D-F) revealed less intense $\mathrm{Pdx} 1$ signal in the developing acini, the epithelial cords, 
Fujitani et al.

Figure 2. Characterization of $P d \times 1^{\Delta I-I I-I I I /-}$ animals. $(A-$ $C)$ Gross analysis of pancreas differentiation in newborn $\mathrm{Pdx}^{+/+}, \mathrm{Pdx}^{+/-}$, and $\mathrm{Pdx}{ }^{\Delta \mathrm{I}-\mathrm{II}-\mathrm{III} /-}$ animals (labeled here as $+/+,+/-$, and $\Delta /-$, respectively). (A) Pancreas tissue outlined. (D) Duodenum; (S) stomach; (SP) spleen; (L) liver. $(B, C)(\mathrm{PR})$ Pancreatic rudiment derived from stunted outgrowth of dorsal pancreatic bud. The bracket in $B$ indicates ectopic spleen tissue frequently observed in $P d \times 1^{-/-}(-/-)$or $P d \times 1^{\Delta I-I I-I I I /-}(\Delta /-)$ mutants. Yellow bile color in duodenum is often seen in -/- mutant animals. $(D-F)$ Histological analysis of gastro-duodenal region (H\&E stain). (D) Normal gastro-duodenal junction with a well-defined pylorus in P1 pup, with continuous lumen joining stomach and rostral duodenum. $(E)$ This region is malformed in -/- littermates (blue bracket). In many -/animals, the region forms a tortuous, sometimes blindended tube that lacks villi and is lined by cuboidal epithelium continuous with the pancreatic rudiment. $(F)$ All $\Delta /$ - animals examined $(n=9)$ have a normal gastroduodenal junction. $(G)$ At P1, endocrine cell aggregations in $+/+$ animals represent immature islets /confocal immunofluroescence: peripheral glucagon-producing cells [red] surround insulin-producing cells [blue]; nuclei counterstained green by Yo-Pro-1). $(H, I)$ Similar confocal immunofluorescence analysis-at higher magnification-of P1 dorsal bud-derived pancreatic rudiment in -/- and $\Delta /$ - mutants showed simple cuboidal epithelium similar to bile duct. Glucagon-producing cells (red, indicated by white arrowheads; nuclei green) were observed adjoining slight evaginations of the endodermal epithelium. $(J-L)$ Immunofluorescence analysis, E16.5 tissues. A lower level of nuclear Pdx1 (blue; nuclei green) was found in the rostral duodenum of $\Delta /$ - animals compared with $+/+$ tissue (-/- tissue lacks signal). $(M, N)$ E12.0 foregut organ development visualized with a lacZ knock-in allele of $P d \times 1\left(P d \times 1^{1 a c Z k o}\right)$. X-gal staining labels (AS) antral stomach, (D) duodenum, (BD) common bile duct, and (DP) dorsal pancreas in both $P d x 1^{\text {lacZko }}$ and $\Delta$-lacZko animals. The ventral pancreatic growth $(\mathrm{VP})$ present in +/lacZko animals is undetected in $\Delta$ /lacZko animals, in which dorsal pancreatic growth is also stunted. Bars: $D-F, 400 \mu \mathrm{m} ; G-L, 50 \mu \mathrm{m}$.

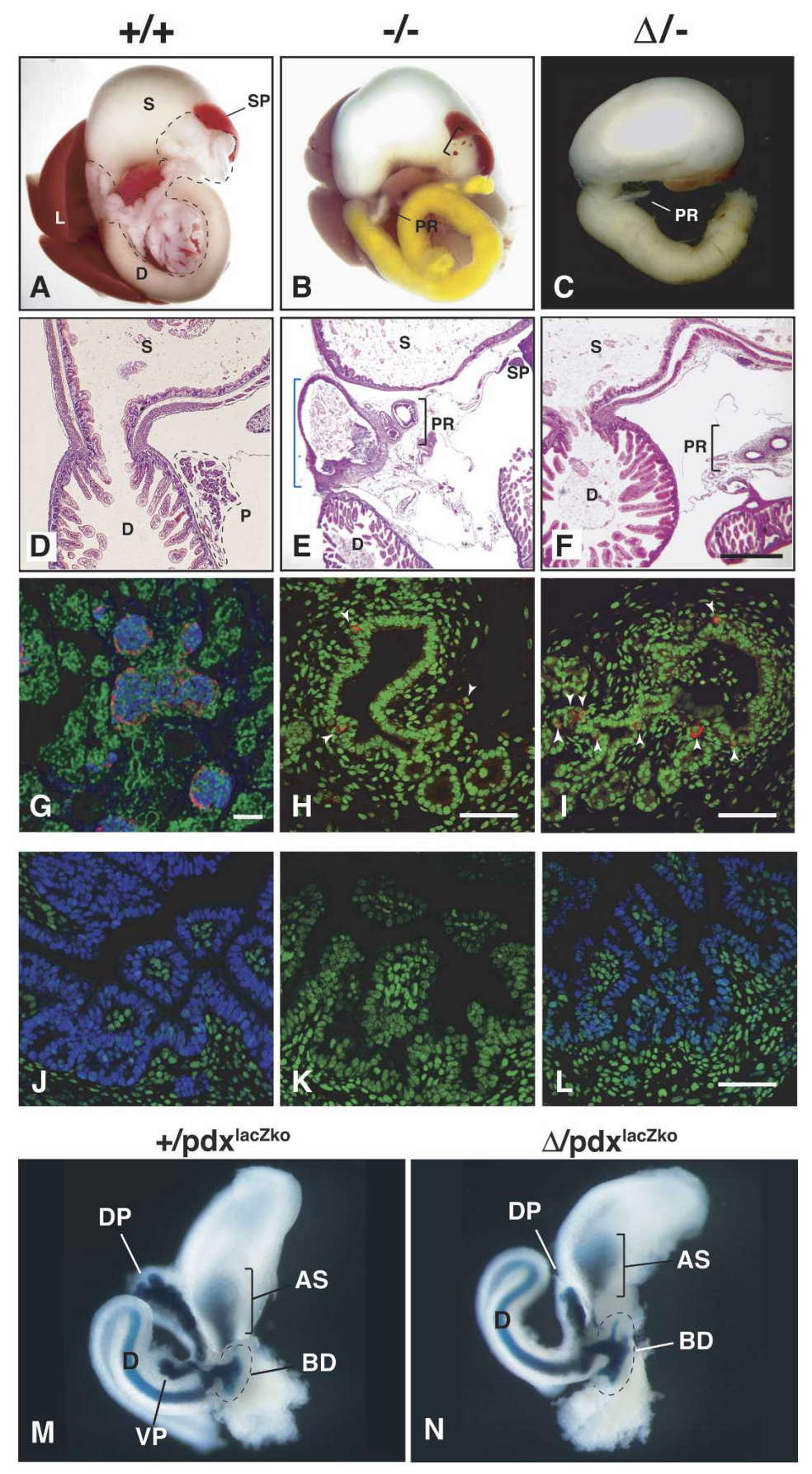

and ductal regions. In addition, there was a notable absence of focal high-level expressing cells, which could represent the precursors of endocrine islet cells based on their number and location tightly abutting the epithelial cords. The reduced level of Pdx1 throughout gestation may account for the reduced mass of acinar tissue and failed $\beta$-cell differentiation in $P d \times 1^{\Delta I-I I-I I I / \Delta I-I I-I I I} \mathrm{mu}$ tants. While it has been reported recently that mature islets in $P d \times 1^{+/-}$animals are susceptible to apoptosis (Johnson et al. 2003), the phenomenon was observed in old mice ( $\sim 5$ mo to $1 \mathrm{yr}$ of age). Together with the finding of an early stage hypoplasia of the $P d \times 1^{\Delta I-I I-I I I / \Delta I-I I-I I I}$ pancreatic bud (Figs. 3, 5), we therefore consider it unlikely that apoptosis is a major contributor to the reduced pancreas mass in $P d \times 1^{\Delta I-I I-I I I / \Delta I-I I-I I I}$ animals. Furthermore, immunodetection of the proapoptotic cleaved form of caspase-3 revealed no increase in apoptosis in E16.5 or E18.5 Pdx $1^{\Delta I-I I-I I I / \Delta I-I I-I I I}$ tissue (data not shown).

\section{Differential requirement for Area I-II-III for dorsal versus ventral pancreas specification}

Since newborn $P d x 1^{\Delta I-I I-I I I / \Delta I-I I-I I I}$ animals appear to lack the ventral pancreas lobe (Fig. 3B), we used the genetic 

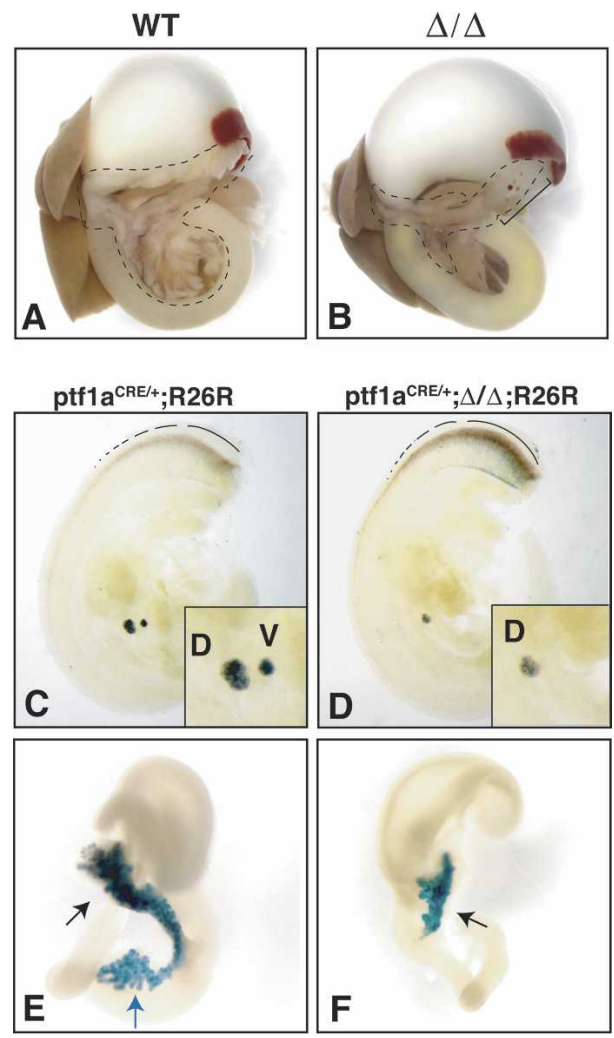

Figure 3. Reduced $P d x 1$ function leads to dysmorphic growth from the dorsal bud and loss of ventral bud specification. $(A, B)$ Pancreas is outlined in newborn pups. Ventral pancreatic lobe (intraduodenal loop region) appears absent in $P d \times 1^{\Delta \mathrm{I}-\mathrm{II}-\mathrm{III} / \Delta \mathrm{I}-\mathrm{II}-\mathrm{III}}$ $(\Delta / \Delta)$ mutants. Bracket in $B$ indicates cystic pancreatic epithelium with associated ectopic splenic tissue. $(C-F)$ Heterozygous mice carrying a Ptf1a ${ }^{C R E}$ knock-in allele $\left(P t f 1 a^{C R E} /+\right)$ together with the Cre-activatable $R 26 R$ reporter allele were used to assess dorsal $(\mathrm{d})$ and ventral $(\mathrm{v})$ bud pancreas specification at E10.5 and E14.5. $(C, D)$ In contrast to normal pancreas specification $(C)$, E10.5 $\Delta / \Delta$ mutants $(D)$ lack the ventral bud region-specific activation of Ptf1a expression and have a reduced dorsal bud. $(E, F)$ At E14.5, the dorsal outgrowth (black arrows) is highly stunted compared with normal, and there is no evidence of ventral lobe-derived cells (blue arrow in normal situation in E). Dotted lines in $C$ and $D$ denote Ptf1a expression in developing spinal cord.

lineage-tracing approach of Kawaguchi et al. (2002) to test whether any ventral pancreatic tissue was specified in these mutants. This approach is powerful because it allows the progeny of cells that activate Ptf1a-an early marker that, within endoderm, is exquisitely specific for only the region that acquires the pancreatic fate-to be followed even if their abnormal genetic constitution causes them to move toward nonpancreatic fates, for example, taking up residence in and differentiating as duodenal cell types (Kawaguchi et al. 2002). We crossed $P t f 1 a^{C R E /+} ; P d \times 1^{\Delta I-I I-I I I /+}$ with $R 26 R ; P d \times 1^{\Delta I-I I-I I I /+}$ mice to obtain Ptf1a $a^{C R E /+}{ }_{;} R 26 R$ and littermate $P t f 1 a^{C R E /+}$; $R 26 R ; P d x 1^{\Delta I-I I-I I I / \Delta I-I I-I I I}$ mice. In these animals, Ptf1adriven Cre expression excises a floxed stop cassette and activates $\beta$-galactosidase expression in a heritable cell- type-independent manner. In normal animals, Ptf1a $a^{C R E /}$ +; R26R labeling traces pancreatic progenitors and their descendants in the duct, acinar, and endocrine lineages
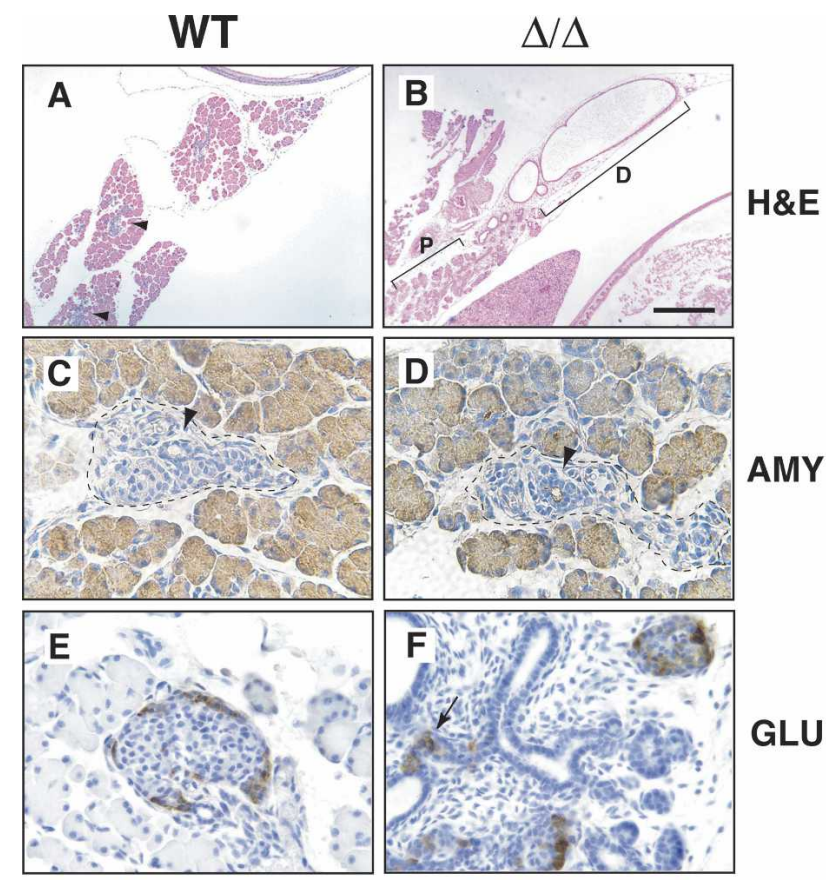

AMY
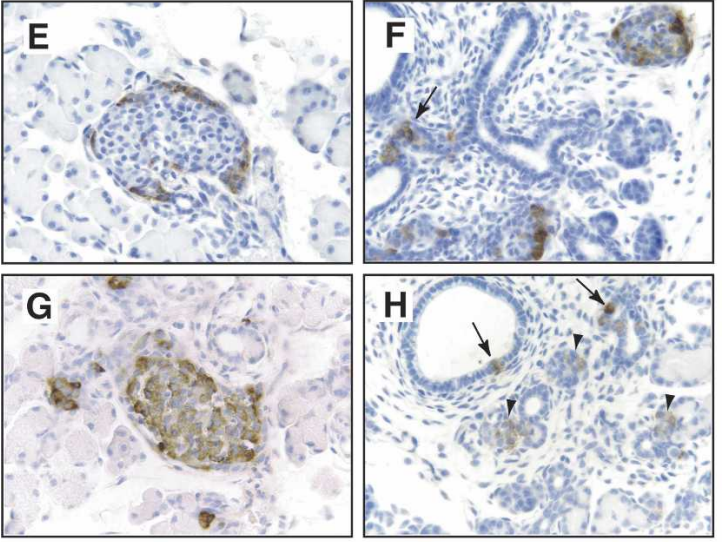

INS
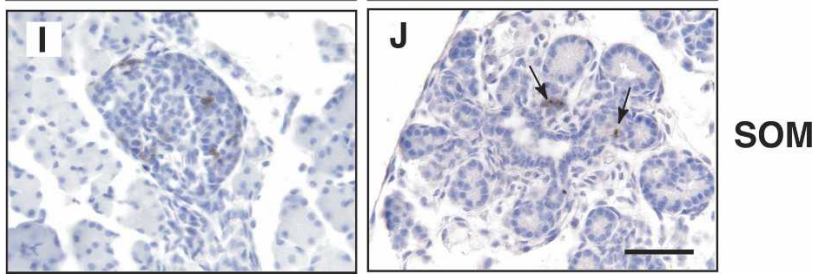

Figure 4. Distal dysmorphogenesis and proximal quasipancreatic differentiation in dorsal pancreas bud of $P d \times 1^{\Delta I-I I-I I I}$ homozygous mice. All tissues are from P1 animals. $(A, B)$ Distal region of dorsal bud tissue (D) differentiates as a simple dilated cystic epithelium (H\&E staining), while gut-proximal tissue $(\mathrm{P})$ undergoes quasipancreatic differentiation (cf. $A$ ), with a transitional zone between these regions. Blue hematoxylin-stained regions in $A$ indicate endocrine compartment forming in newborn $+/+$ pancreas. (C-I) Immunohistochemical comparison of normal and gut-proximal pancreatic tissue of $P d x 1^{\Delta I-I I-I I I / \Delta I-I I-I I I}(\Delta / \Delta)$ animals. Well-polarized acinar cells express almost normal levels of amylase (AMY) $(C, D)$, and there are substantial numbers of disorganized glucagon-producing cells (GLU) $(E, F)$, but only a few, weakly positive insulin-expressing cells $(G, H$; INS, arrowheads in $H)$. $(H)$ Some insulin-producing cells are located in or adjacent to ductal epithelium (arrows). (I,J) Somatostatin-producing cells (SOM) are found as small cell clusters or isolated cells in close proximity to ducts. Forming endocrine compartments are outlined in $C$ and $D$. Ducts are denoted by black arrowheads. Bars: $A-B, 400 \mu \mathrm{m} ; C-J, 50 \mu \mathrm{m}$. 
Fujitani et al.

Figure 5. Immunohistochemical assessment of Pdxl protein expression levels with various combinations of $P d x 1$ deletion alleles. Tissue processing and immunostaining in parallel allowed comparison of cellular Pdx1 level; representative images are from serial section analysis of at least three embryos for each genotype. Confocal imaging and post-processing was identical for all samples; background is shown deliberately, so that the specific Pdxl signal in the dorsal pancreas (DP) can be judged against it. $(A-C)$ E12.0 tissues. Different combinations of mutant alleles affect Pdx1 levels in the early pancreas anlagen; signal intensity is similar in all cases in caudal stomach epithelium (CS). $(D-F)$ E16.5 tissues. Embryos homozygous for the $P d \times 1^{\Delta I-I I-I I I}$ allele $(\Delta / \Delta)$ lack the focal high-level Pdxl-expressing cells (arrowheads) seen in normal tissue, with a significantly lower signal through the developing epithelial cords and acinar clusters. $(G, H)$ Confocal immunofluorescence analysis on parallel-processed tissues from 4-wk-old mice from $+/+$ and $\Delta /+$ adult islets (insulin, green; $P d x 1$, red). We noted an increased number of non- $\beta$ cells (insulin ${ }^{-}$) in $\Delta /+$ islets (Fig. 7, Supplementary Fig. 3). Bars: $A-C, 50 \mu \mathrm{m} ; D-F, 50 \mu \mathrm{m} ; G, H, 50 \mu \mathrm{m}$.
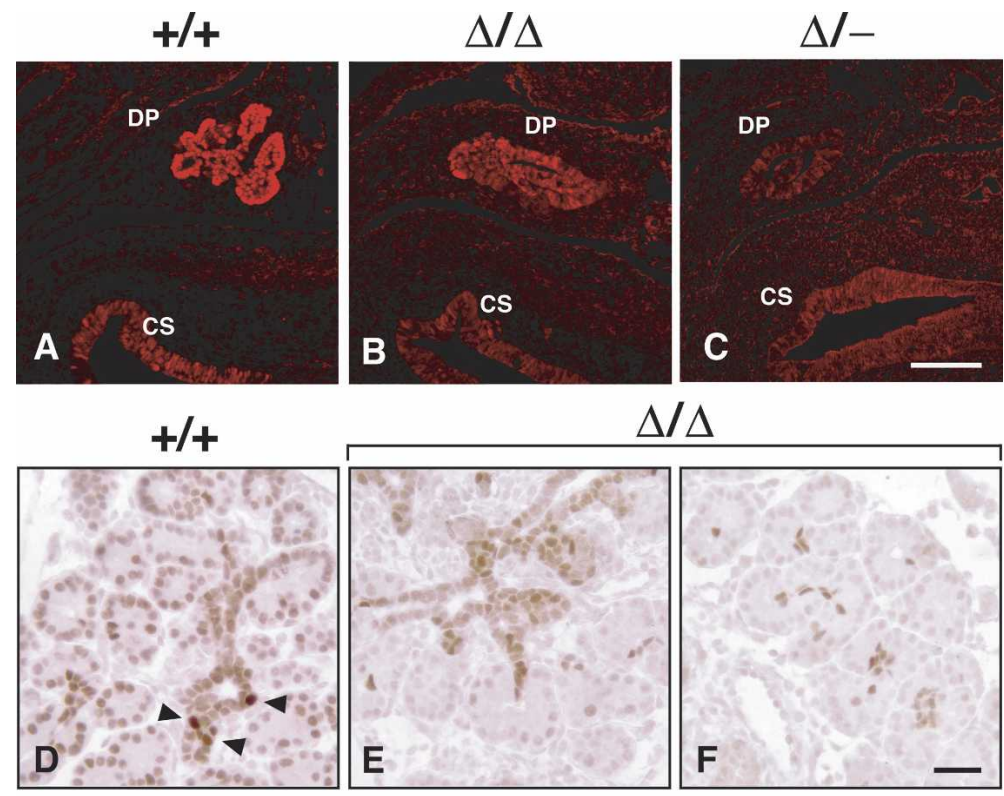

$\Delta / \Delta$
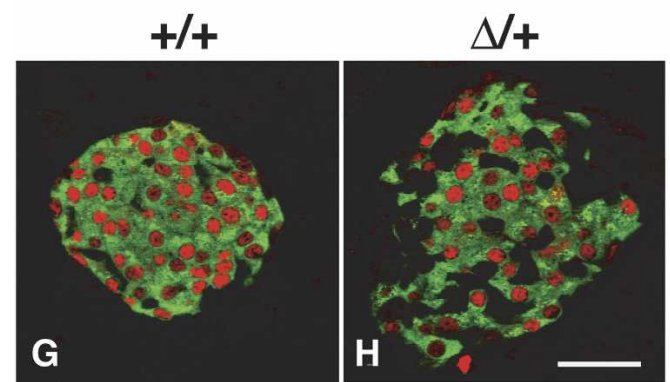

(Kawaguchi et al. 2002). Therefore, both dorsal and ventral pancreatic buds at E10.5 and both pancreatic lobes at E14.5 were labeled robustly in $P t f 1 a^{C R E /+} ; R 26 R$ mice (Fig. 3C,E). In contrast, at both the early and midgestation time points, there was no formation of putative ventral pancreas or its progenitors in $P d \times 1^{\Delta I-I I-I I I / \Delta I-I I-I I I} \mathrm{mu}-$ tants. Importantly, no ventral pancreas-specified progenitors led to progeny that differentiated as either pancreatic or intestinal cell types in the gut tube. This labeling strategy also showed that the dorsal bud was already stunted at the earliest time point, and was much smaller than normal at midgestation (Fig. 3D,F). The failure to activate Ptf1a expression shows that a specific level and/or timing of Pdx1 expression is required for the specification of the ventral pancreas; i.e., the production or survival of Ptf1a-expressing progenitor cells.

Gastro-duodenal defects limited to enteroendocrine cells in $\mathrm{Pdx} 1^{\Delta \mathrm{I}-\mathrm{II}-\mathrm{III} /-}$ mutants

It was previously shown that $P d \times 1^{-/-}$(global proteinnull) animals display various defects in addition to pancreas agenesis, including a distorted pylorus, absence of Brunner's glands, and localized reductions in enteroendocrine cell numbers (Larsson et al. 1996; Offield et al.
1996; Jepeal et al. 2005). Many $P d \times 1^{-/-}$animals had pyloric atresia and the rostral-most duodenal cavity had an undulating appearance, lacking villi, that was lined by a simple cuboidal epithelium continuous with the common bile duct and dorsal pancreatic ductule (Fig. 2E; Offield et al. 1996). At P1, a substantial proportion of $P d \times 1^{-1-}$ pups showed stomach distension caused by poor gastric emptying likely associated with the malformed gastro-duodenal junction (Offield et al. 1996). In contrast, a distended stomach was not observed in $P d \times 1^{\Delta I-I I-I I I /-}$ mutants $(n=12)$. The gastro-duodenal junction developed normally in $P d x 1^{1 I-I I-I I I /-}$ mice, and the smooth muscle bands of the pyloric ring, columnar epithelium of the rostral duodenal villi (Fig. 2F), and Brunner's glands (Supplementary Fig. 1) were all well formed. Pdx1 protein was detected at E16.5 in the rostral duodenum (Fig. 2J-L) and antral stomach epithelium (data not shown) of $P d \times 1^{\Delta I-I I-I I I /-}$ animals, although the level was lower than in $P d \times 1^{+/+}$animals (Fig. 2J,L); similar findings were made at E18.5 (data not shown). Therefore, while Pdx1 expression in the $P d \times 1^{\Delta I-I I-I I I /-}$ animals is sufficient for normal morphological formation of the gastro-duodenal junction and Brunner's gland differentiation, the reduced level, or abnormalities in the spatiotemporal expression profile, cannot support pancreatic development over and above the level seen in $P d \times 1^{-1-}$ mutants. The very low level of 
Pdx1 in the $P d \times 1^{\Delta I-I I-I I I /-}$ dorsal pancreas detected at E12.0 (Fig. 5) was transient, not being detected at late gestation or in neonates (data not shown).

We and others have reported that $P d \times 1^{-/-}$(proteinnull) animals have reduced numbers of enteroendocrine cells in the rostral duodenum and adjacent antral stomach (Larsson et al. 1996; Offield et al. 1996; Jepeal et al. 2005). Because Area I-II-III contains enhancer-like elements that drive reporter expression in a pancreatic endocrine-specific manner in transgenic animals and cell culture (Wu et al. 1997; Gerrish et al. 2000; Gannon et al. 2001), it may also allow $P d x 1$ expression to reach a specific threshold associated with specification, differentiation, and/or maintenance of enteroendocrine cell types. As shown in Figure 6, there was a dramatic reduction in $P d \times 1^{-1-}$ animals of gastrin-producing cells in antral stomach (100\% loss at P7) and GIP-producing cells in rostral duodenum $(96.5 \%$ reduction at E18.5), confirming a central requirement for $P d x 1$ in establishing these cell populations. Moving from $P d x 1^{\Delta I-I I-I I I / \Delta I-I I-I I I}$ to $P d \times 1^{\Delta I-I I-I I I /-}$ led to a step-wise reduction in gastrin-producing cells (Fig. 6A; $63.4 \%$ and $77.8 \%$ reduction, respectively) and GIP-producing cells (Fig. 6B; 51.3\% and $83.0 \%$ reduction, respectively), without significant alteration in the number of serotonin-producing cells (Fig. 6C). These results suggest that gastrin- and GIP-producing cells require wild-type levels and/or timing of Pdx1 expression that is dependent upon the cis-activity of Area I-II-III.

$\mathrm{Pdx}^{\mathrm{\Delta I}-\mathrm{II}-\mathrm{III} /+}$ animals have impaired islet architecture and maturity-onset diabetes

Mice with a heterozygous deletion of Area I-II-III $\left(P d \times 1^{\Delta I-I I-I I I /+}\right)$ were fully viable, fertile, and indistinguishable in body weight from control littermates. They had a normal-sized pancreas (data not shown), with an islet size distribution similar to wild type (Supplementary Fig. 2). However, the islets of $P d \times 1^{\Delta I-I I-I I I /+}$ animals had a severely altered structure, containing significantly increased numbers of PP- and glucagon-producing cells compared with age-matched wild-type littermates (Supplementary Fig. 3). Glucagon-producing cells in $P d \times 1^{\Delta I-I I-I I I /+}$ islets were most often intermixed with $\beta$ cells, and not peripherally located as in wild type (Fig. 7A-C). In wild-type islets, Glut2, a key component of the glucose-stimulated insulin-secretion machinery (Tho- rens 2001), was localized to the $\beta$-cell membrane (Fig. $7 \mathrm{D}, \mathrm{G})$, but undetectable in the majority of islets in $P d \times 1^{\Delta I-I I-I I I /+}$ animals, while $P d \times 1^{+/-}$littermates showed moderately reduced Glut2 (Fig. 7, cf. E,H and F,I), as reported previously (Ahlgren et al. 1998; Brissova et al. 2002; Johnson et al. 2003). These results indicate that Area I-II-III plays a key role in establishing and/or maintaining the normal ratio of pancreatic endocrine cell types, with heterozygous deletion also affecting the differentiated state of the $\beta$ cells.

The islet architecture alterations in $P d x 1^{\Delta I-I I-I I I /+}$ mice were associated with highly defective glucose homeostasis. Blood glucose levels were similar in newly weaned 3-wk-old ad libitum-fed $P d \times 1^{\Delta I-I I-I I I /+}, P d \times 1^{+/+}$, and $P d \times 1^{+/-}$littermates (data not shown). At $10 \mathrm{wk}$, however, $P d \times 1^{\Delta I-I I-I I I /+}$ mice showed statistically higher glucose levels (Fig. 8C) and significantly reduced serum insulin (Fig. 8E), suggesting the onset of defective islet function. A gross evaluation of overall islet function was made by IP-GTT at 8-11 wk of age (Fig. 8A). Consistent with previous reports (Dutta et al. 1998; Brissova et al. 2002; Johnson et al. 2003), $P d \times 1^{+/-}$mutant animals had impaired glucose clearance compared with wild type. However, $P d x 1^{\Delta I-I I-I I I /+}$ animals that were, importantly, derived from the same litters (see Discussion), displayed even worse glucose clearance. A substantial number of the $P d x 1^{\Delta I-I I-I I I /+}$ animals showed off-scale glucose measurements (i.e., >600 mg/dL) at the early IP-GTT time points (see the legend for Fig. 8). Measuring plasma insulin from the same samples shown in Figure 8A showed that it was inappropriately low in $P d \times 1^{\Delta I-I I-I I I /+}$ mice at 15 min after glucose challenge, with an overall delayed and smaller increase (Fig. 8B). There was no appreciable alteration in total cellular insulin content in $P d \times 1^{\Delta I-I I-}$ III/+ pancreata (Fig. 8G); furthermore, there was no hyperglucagonemia or change in pancreatic glucagon (Fig. $8 \mathrm{~F}, \mathrm{H})$. Thus, disruption of insulin secretion in $P d x 1^{\Delta I-I I-I I I /+}$ mice appears to be the major contributor to the observed hyperglycemia, and an underlying mechanistic defect could be the drastically reduced Glut 2 in the $\beta$ cells of these mice.

\section{Discussion}

Our experiments reveal an essential in vivo function in foregut organogenesis for the conserved upstream Area I-II-III cis-regulatory region of $P d x 1$. A major finding from these studies is that the various organs and tissue
A

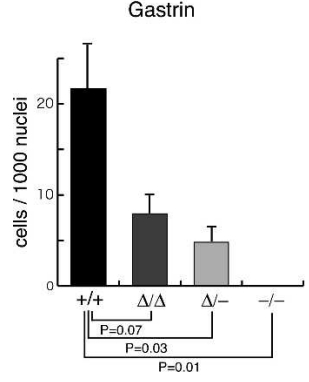

B

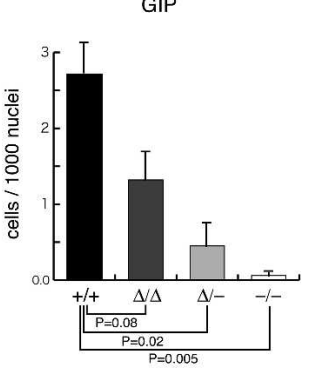

C

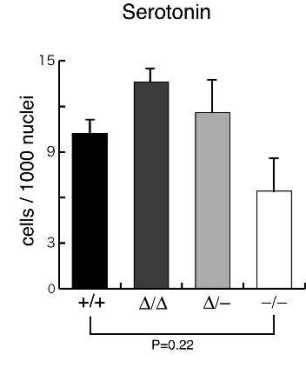

Figure 6. Frequency of gastrin- and GIP-producing cells as a function of $P d x 1$ genotype. Sections analyzed were E18.5 for GIP- and serotonin-producing cells, and P7 for gastrin-producing cells. Results are from analyzing three mice of each genotype (see Materials and Methods for tissue sampling protocol). The $Y$-axis represents the number of gastrin-, GIP-, or serotonin-producing cells per 1000 epithelial nuclei; data expressed as mean \pm SE $(n=3)$. 
Fujitani et al.

Figure 7. The $P d x 1^{\Delta I-I I-I I I /+}$ genotype leads to severely compromised mature islet architecture and endocrine differentiation. All tissues analyzed were from 4-wk-old mice. $(A-C) P d \times 1^{\Delta I-I I-I I I /+}(\Delta /+)$ mice show a reproducible increase and intra-islet scattering of glucagon cells (see also Supplementary Fig. 3) $(D-F) \beta$-Cell-selective expression of Glut2 is modestly decreased in $P d \times 1^{+-}(+\mid-)$animals, but is absent in $\Delta /+$ animals (arrowheads indicate ducts). $(G-I)$ High magnification of bracketed region in $D-F$ (arrowheads in $H, I$ indicate autofluorescent erythrocytes in capillaries to show gain setting equivalence across the three panels; three erythrocytes clustered in $H)$. $(J-L)$ Frequency of PP cells is dramatically increased in $\Delta /+$ animals; somatostatin cells are relatively unchanged in number and location (see also Supplementary Fig. 3). Bars: $A-F, 50 \mu \mathrm{m} ; G-I, 12.5$ $\mu \mathrm{m} ; J-L, 50 \mu \mathrm{m}$.
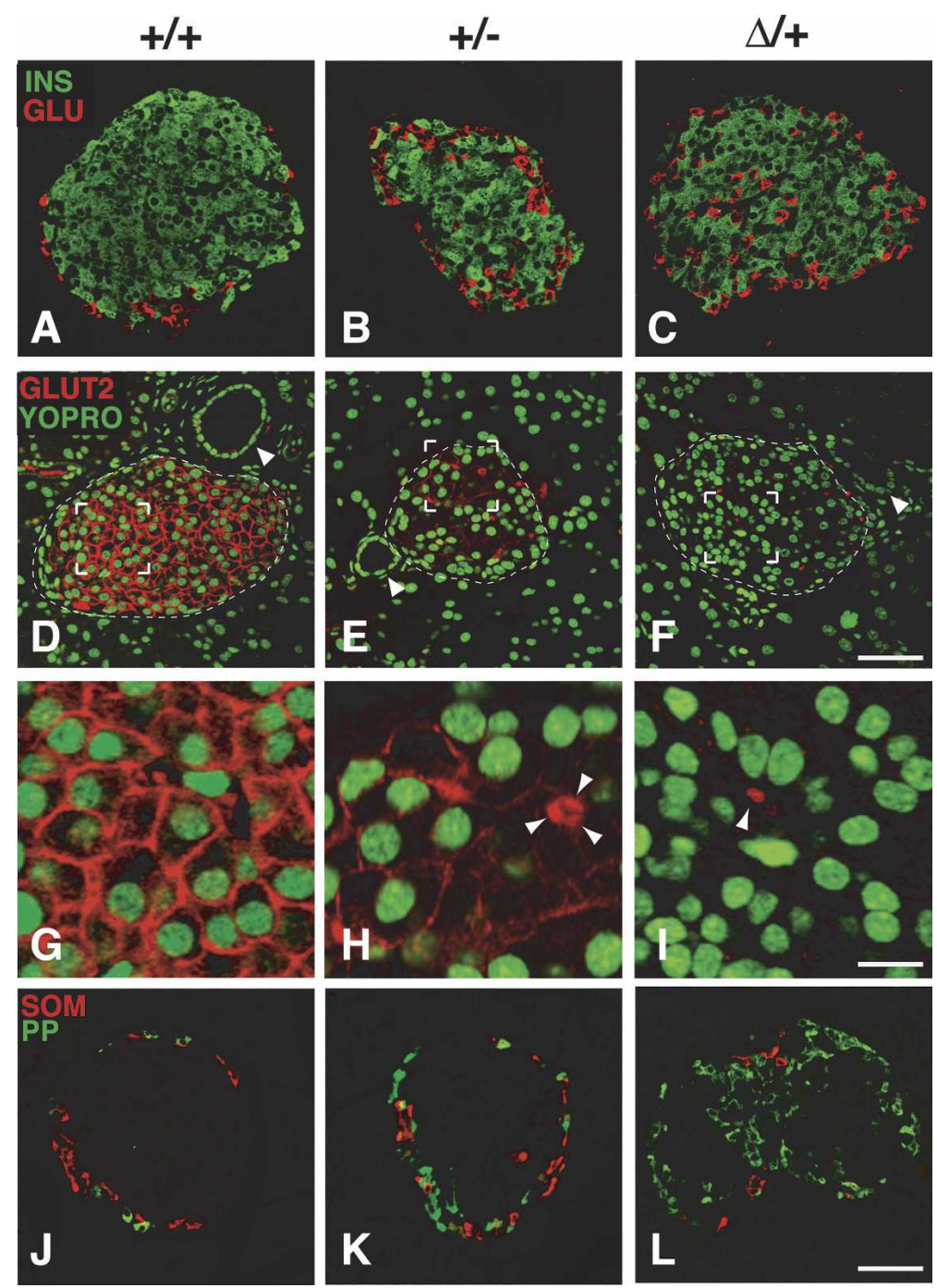

derivatives of the posterior foregut (caudal stomach, pylorus, rostral duodenum, and pancreas) are differentially sensitive to the quality of $P d x 1$ expression-i.e., the spatiotemporal and level characteristics-which is substantially altered when Area I-II-III is deleted. Moreover, there is a differential requirement for $P d \times 1$ in specifying the dorsal or ventral pancreatic bud, and our results suggest that the dorsal bud contains different classes of progenitors with respect to their ability to move through the pancreatic differentiation program. These findings set the stage for the future iterative dissection in vivo of specific subregions and selected motifs within this $\sim 1-\mathrm{kb}$ region, which contains highly clustered binding sites for a variety of well-known endoderm and pancreas transcription factors. Based upon the level of analysis compared with other pancreas genes, $P d \times 1$ could be considered an important reference gene, as it may represent a nexus for the complex signaling and transcriptional inputs that orchestrate proliferation, outgrowth, and differentiation of this organ. It will be particularly relevant to determine how regionalized intercellular signals lead to the dynamic level and timing of $P d x 1$ expression in specific cell types through the assembly of transcriptional complexes at the various motifs in Area I-II-III, and how these control lineage diversification decisions or, later, affect the maintenance of the mature cell state. Clearly, a substantial hurdle to overcome in such studies will be the current paucity of markers that define critical progenitor subtypes in the pancreatic endocrine differentiation program. Information on the networks orchestrating endodermal progenitor cell differentiation could have a large impact on protocols for directed tissue differentiation leading toward cell-based therapies for diabetes.

\section{Dosage effects of Pdx1 on foregut development and pancreas organogenesis}

Figure 9 summarizes how foregut development is affected by the various combinations of $P d \times 1^{\Delta I-I I-I I I}$, $P d \times 1^{-}$, and wild-type alleles. Notably, removing Area III-III does not inactivate the gene, but instead generates a hypomorphic allele in terms of its level and spatiotemporal expression characteristics. This finding is consistent with the recent characterization of cell-type-spe- 
A

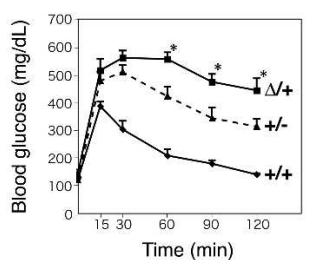

C

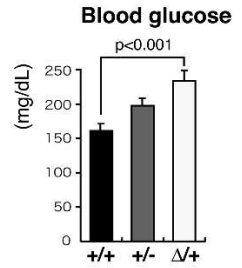

$\mathbf{E}$

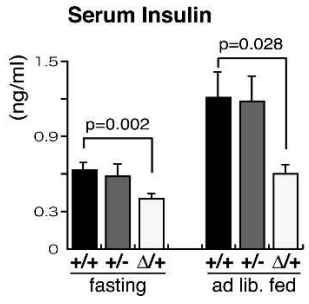

G

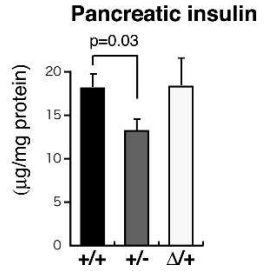

B

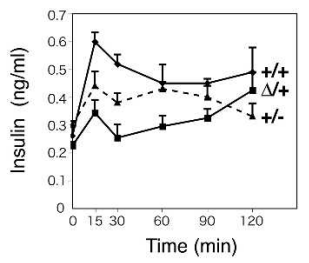

D

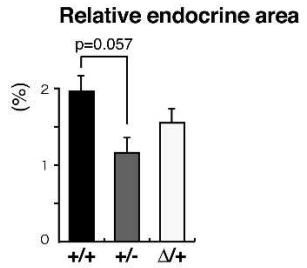

$\mathbf{F}$

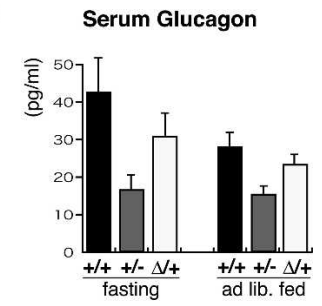

H

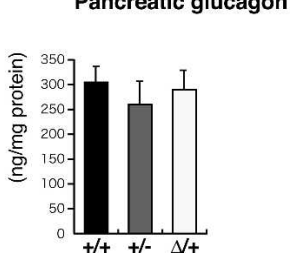

Figure 8. Impaired glucose homeostasis in $P d x 1^{\Delta I-I I-I I I /+}$ animals. Glucose clearance $(A)$ and corresponding serum insulin levels $(B)$ during IP-GTT (data from 8- to 11-wk-old female offspring from three litters resulting from crosses of $P d \times 1^{+/-}[+/-]$ with $P d x 1^{\Delta I-I I-I I I /+}[\Delta /+]$ mice; $N$ analyzed $=4+/+, 5+/-$, and 5 $\Delta /+) .\left(^{\star}\right) P<0.05$ compared with $+/-$ mice. Note: In $A$, two mice showed 30 and 60 min off-scale measurments, which were assigned values of $600 \mathrm{mg} / \mathrm{dL}$ for the mean calculated here. $(C)$ Serum glucose levels in $+/+(n=7),+/-(n=6)$ and $\Delta /+$ littermates $(n=7)$ in ad lib. fed 10-wk-old mice. $(D)$ Relative pancreatic endocrine area, 10-wk-old mice, as a percentage relative to the whole pancreas area (means $\pm \mathrm{SE}, n=3)$. $(E)$ Serum insulin levels in $+/+(n=10),+/-(n=6)$, and $\Delta /+(n=10)$ adults $(8-11$ wk) in overnight fasting and ad lib. fed conditions. $(F)$ Serum glucagon levels in $+/+(n=10),+/-(n=7)$, and $\Delta /+(n=10)$ adults (8-11 wk old) in overnight fasting and ad lib. fed conditions. $(G, H)$ Total extractable pancreatic insulin and glucagon levels in $+/+(n=6),+/-(n=5)$, and $\Delta /+(n=7)$ adults $(8-11 \mathrm{wk}$ old $)$ during ad lib. feeding.

cific, orientation-independent enhancer activities within Areas I and II (Van Velkinburgh et al. 2005). In several tissues, the level of nuclear Pdx1 produced from the $P d \times 1^{\Delta I-I I-I I I}$ allele was notably lower than from a wildtype allele. In addition, the high-level expression that is normally present in subsets of the progenitor-harboring pancreatic epithelium during the secondary transition stages of pancreatic organogenesis was absent in the $P d \times 1^{\Delta I-I I-I I I / \Delta I-I I-I I I}$ state. Our preliminary data (data not shown) suggest that Pdx1 expression from the Pdx $1^{1^{I-I I-I I I}}$ allele within the foregut epithelium at approximately E9.5 is delayed substantially compared with wild type. Thus, both the spatiotemporal and level characteristics of $P d \times 1$ are affected by removing Area I-II-III.

The overall picture that emerges is that the morphogenesis of the caudal stomach, pylorus, and rostral duodenum (including its villi and Brunner's glands) exhibit the lowest sensitivity to reducing the quality of $P d \times 1$ gene expression. Within the foregut region gut epithelium, however, there remains a requirement for normal $P d x 1$ expression for the differentiation of GIP- and gastrin-producing enteroendocrine cells. In contrast to gut morphogenesis, pancreas development is remarkably sensitive to interference with $P d x 1$ function. The ventral bud is not specified in the $P d \times 1^{-/-}, P d \times 1^{\Delta I-I I-I I I /-}$, and $P d \times 1^{\Delta I-I I-I I I / \Delta I-I I-I I I}$ conditions, and while the gut-proximal region of the $P d \times 1^{\Delta I-I I-I I I / \Delta I-I I-I I I}$ dorsal bud forms abnormal pancreatic tissue, the distal region only forms a duct-like cystic epithelium.

\section{Dorsal versus ventral pancreas specification programs and progenitor classes}

Our lineage-tracing experiments showed that it is not just ventral pancreatic bud outgrowth that is abrogated in $P d \times 1^{\Delta I-I I-I I I / \Delta I-I I-I I I}$ animals, but that its initial specification is blocked, as evaluated via the Ptf1a-Cre/R26R method. The failure to activate Ptf1a expression shows that ventral bud specification has a more stringent threshold requirement for $\mathrm{Pdx} 1$, because the delayed and reduced expression in the $P d x 1^{\Delta I-I I-I I I / \Delta I-I I-I I I}$ configuration at least initiates the dorsal bud pancreatic program. Differences in the genetic pathways of dorsal versus ventral pancreas differentiation are also known for other genes, such as Is11, Hlxb9, and Flk1 (Ahlgren et al. 1997; Harrison et al. 1999; Li et al. 1999; Yoshitomi and Zaret 2004), but our approach is different in using lineage labeling to assess the initial tissue specification process.

In $P d \times 1^{\Delta I-I I-I I I / \Delta I-I I-I I I}$ animals, the cystic epithelium seen in gut-distal regions of the dorsal pancreas contrasted the more differentiated gut-proximal pancreatic region. It is possible that the distinct differentiation of the two regions arises through interactions with surrounding tissues (intestine, mesenchyme), and/or that initially intermixed progenitor populations become spatially separated during bud outgrowth. In either case, the differential response of dorsal pancreatic progenitors to reduced quality of $P d x 1$ expression suggests that the normal pancreatic buds harbor qualitatively different progenitors. The particular response of distinct progenitor populations to the titer or timing of $\mathrm{Pdx} 1$ expression may be relevant to methods of enforcing pancreatic differentiation from surrogate cells. ES cell differentiation in the presence of activin can produce endoderm, and allow formation of a small proportion of pancreas-like cells (Kubo et al. 2004; Tada et al. 2005). More efficient commitment of cells to the pancreatic fate may require 
Figure 9. Schematic summary: differential effects of $P d x 1$ dosage on pancreas and foregut epithelial development. The previous protein-null (Offield et al. 1996) and $\Delta \mathrm{I}$-II-III alleles are represented. Homozygous protein-null embryos frequently lack villi in the rostral-most duodenum (their variable presence indicated by lighter shading and dotted lines), with severe pyloric dysmorphology (light-orange plug). Brunner's glands are absent from the duodenal collar region adjacent to the pylorus. Not represented here is the enteroendocrine cell deficiency in stomach and duodenum (see text). One copy of the partially functional $\Delta \mathrm{I}$-II-III allele restores differentiation of the pylorus, Brunner's glands, and rostral duodenal villi, but the pancreas remains highly abrogated (Figs. 3, 4). Embryos homozygous for the $\Delta \mathrm{I}$-II-III allele exhibit

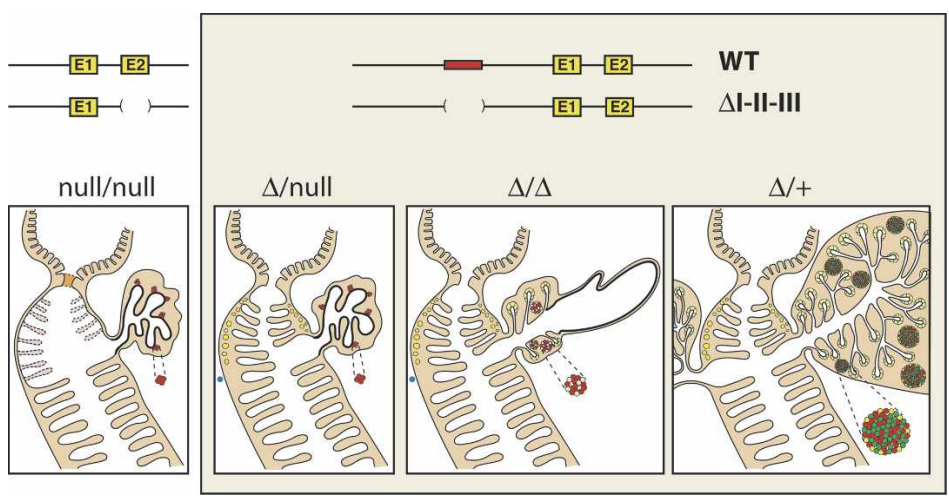
quasi-pancreatic differentiation of a dorsal bud-derived pancreatic rudiment proximal to the gut tube, and a distal cystic epithelium (Fig. 4). (Blue dots) Lack of ventral bud specification as marked by Ptf1a-Cre;R26R lineage tracing (Fig. 3). The $\Delta /+$ combination allows full-sized outgrowth of both dorsal and ventral buds, but the islets are highly abnormal (Fig. 7). (Yellow) Acini and Brunner's glands; (red) glucagon-producing $\alpha$ cells; (green) insulin-producing $\beta$ cells.

careful control of the level of Pdx1 expression at precise stages of differentiation.

\section{Pdx1 regulation in enteroendocrine and gut epithelial cell differentiation}

Our previous studies (Wu et al. 1997; Gerrish et al. 2000, 2001; Gannon et al. 2001) in transgenic mice and in vitro cell culture focused on pancreatic enhancer-like activities of Area I-II-III and not whether this region regulates $P d \times 1$ in gut enteroendocrine cells. Gastrin-producing cells in the antral stomach-pyloric mucosa and GIP-producing cells in the rostral duodenum strictly depend on the presence of Area I-II-III, and are thus similar to pancreatic $\beta$ cells. This result strongly suggests that overlapping sets of upstream transcriptional regulators for $P d \times 1$ drive endocrine differentiation in the pancreas and gut. There is evidence that transcriptional regulators of endocrine pancreas development, such as Ngn3, NeuroD, Nkx6.1, Pax6, and Pax4, are essential for enteroendocrine differentiation (Naya et al. 1997; Larsson et al. 1998; Larsson 2000; Jenny et al. 2002; Lee et al. 2002). Of these factors, null mutants for Pax6 have a characteristic phenotype in the enteroendocrine lineages-elimination of duodenal GIP cells and gastrin cells in the antral stomach-that is reminiscent of $P d x 1$-null mutants (Larsson et al. 1998). Pax6 can bind to Area II in the Pdx1 promoter (Samaras et al. 2002), suggesting a fundamental role in the endocrine-specific regulation of the $P d \times 1$ gene in both pancreas and gut.

The enterocytes and Brunner's gland cells, which are affected in $P d x 1$-null mice, underwent normal differentiation in $P d x 1^{\Delta I-I I-I I I / \Delta I-I I-I I I}$ or $P d \times 1^{\Delta I-I I-I I I /}$ animals. Other elements must therefore regulate the basal transcription of $P d \times 1$ or generate enough cis-activation for the normal differentiation of the caudal stomach, pylorus, bile duct, and duodenum. Currently, we hypothesize that distal 5' regions, such as the phylogenetically conserved Area IV (Sharma et al. 1997; Gerrish et al. 2004), or more distributed cis-regulatory motifs, are involved in driving normal expression in the duodenum and stomach (D. Boyer and C. Wright, unpubl.). Future discoveries may reveal that potentiation of Area I-II-III activity by these elements (Gerrish et al. 2004) fine-tunes $P d x 1$ expression in the pancreatic endocrine lineage.

\section{Etiology of the diabetic phenotype in $\mathrm{Pdx} 1^{\Delta \mathrm{I}-\mathrm{II}-\mathrm{III} /+}$ mutants}

By several measurements-serum insulin and glucose levels under ad lib. feeding or glucose challenge, abnormal islet architecture- $P d \times 1^{\Delta I-I I-I I I /+}$ mice are more severely affected than their $P d \times 1^{+/-}$littermates, despite similar pancreatic insulin content. One major contributor to the phenotype may be the lack of Glut2 on the $\beta$ cells of $P d x 1^{\Delta I-I I-I I I /+}$ islets compared with the moderate reduction in $P d \times 1^{+/-}$mice (Fig. 7). Glut2 is required for glucose-stimulated insulin secretion in mice (Guillam et al. 1997) and is a $\beta$-cell gene target of Pdxl (Waeber et al. 1996). Quantitative Western blot analysis (data not shown) detected a similar overall Pdx1 level in $P d \times 1^{\Delta I-I I-I I I /+}$ and $P d \times 1^{+/-}$pancreata, and $P d x 1^{\Delta I-I I-I I I /+}$ islets faithfully expressed Pdx1 in $\beta$ cells (Fig. 5G,H), suggesting that it is not lower Pdx1 levels or inconsistent expression that lead to the lack of Glut2. We hypothesize that an underlying defect in islet genesis and organization is responsible for a profound disruption of the glucose-sensing machinery. Other mouse models in which peripheral islet cells mix into the islet core, such as enforced expression of HNF6 or dominant-negative HNF1 $\alpha$ (Gannon et al. 2000; Yamagata et al. 2002), also show absent or largely reduced Glut2 expression. Mixing of peripheral cell types with $\beta$ cells may disrupt the gap junctional or other coupling that is involved in a concerted, efficient insulin release (Caton et al. 2002).

\section{Heterozygous enhancer deletion and the mechanism of disruption of islet morphology}

The mixed islet phenotype and abnormally high $\alpha, \delta$, and PP cell numbers in $P d \times 1^{\Delta I-I I-I I I /+}$ mice compared with 
wild-type or $P d x 1^{+/-}$mice (Supplementary Fig. 3) suggests that loss of one copy of the Area I-II-III region leads to defective lineage allocation from the endocrine progenitors. At the current time, mostly related to a lack of knowledge on how to mark specific progenitor classes, this result cannot be explained mechanistically. However, we consider it unlikely that the difference is attributable to genetic background differences between the various mutant combinations. All comparisons between wild-type, $P d \times 1^{\Delta I-I I-I I I /+}$, and $P d \times 1^{+/-}$were between siblings, and the results were consistent among multiple litters. Furthermore, analysis of mice bearing the floxed allele from which the $P d \times 1^{\Delta I-I I-I I I}$ allele was derived showed no defects in islet architecture in $P d x 1^{f l o x I-I I-I I I /+}$, $P d \times 1^{\text {floxI-II-III/floxI-II-III }}$, or $P d x 1^{\text {floxI-II-III/- }}$ pancreata (data not shown). One potential reason that heterozygosity for Area I-II-III is more severe than heterozygosity for the protein-coding region could be that its enhancer activity also affects the expression of another gene involved in islet progenitor differentiation. Candidate genes are the homeobox genes flanking $P d x 1$ in the "Parahox cluster", Gsh1 and $C d x 2$. Both genes may be expressed in the developing pancreas and mature islets (Rosanas-Urgell et al. 2005), and Cdx2 can transcriptionally activate Glucagon in pancreatic cell lines (Andersen et al. 1999). It is also possible that deletion of Area I-II-III eliminates a repressor element resulting in ectopic expression of Pdx1; however, no ectopic expression was observed in any tissues at any of the stages examined. Another possibility is that Area I-II-III heterozygosity blunts a largescale fold increase in Pdxl expression that is linked to the channeling of cells from a common endocrine precursor pool toward the $\beta$-cell fate. Lineage-tracing experiments show that all pancreatic endocrine precursors express $P d x 1$ (Gu et al. 2002), and in the mature organ Pdxl is found at the highest levels in $\beta$ cells (Guz et al. 1995). The $P d x 1^{\Delta I-I I-I I I}$ allele produces a substantial baseline amount of Pdx1 in immature endoderm (Figs. 2L, 5B), but is deficient for high-level expression (Fig. 5D-F), consistent with the idea (see above) that Area I-II-III trans-activators promote high-level $\beta$-cell-selective expression. It is therefore plausible that the fold increase between baseline and maximum expression levels would be reduced in $P d \times 1^{\Delta I-I I-I I I /+}$ mice compared with wild type, while the active allele in +/- mice would still achieve a fold-increase similar to wild type. If the efficiency of converting common endocrine precursors to committed $\beta$-cell progenitors depends on the degree of up-regulation of $P d x 1$ expression at a specific lineage commitment point, then the selective impairment to high-level expression could lead to cells defaulting to the other endocrine fates.

\section{Conserved Pdx1 enhancers as targets for MODY syndrome}

Various transcriptional activators implicated in the human MODY syndrome, or as major regulators of endoderm development, have been shown capable of binding within Area I-II-III: HNF1 $\alpha$, Foxa2/HNF3 $\beta$, Pdx1 itself,
Maf, Pax6, and HNF6 (Gerrish et al. 2000, 2001; Marshak et al. 2000; Ben-Shushan et al. 2001; Samaras et al. 2002, 2003; Jacquemin et al. 2003). In addition, MODY factors have been reported to synergistically regulate $P d x 1$ expression in $\beta$ cells in vivo (Shih et al. 2002). These findings suggest that Area I-II-III may be a major site of action for transcription factors implicated in MODY. Consistent with this hypothesis, we found that heterozygous deletion of Area I-II-III results in post-weaning diabetes as early as 4 wk of age. Although mutations in the equivalent region of human IPF1 have not yet been identified, it is possible that even heterozygous Area I-II-III mutations/deletions, or reductions in the level or activity of trans-acting MODY factors that operate through Area I-II-III, could be a significant underlying influence in MODY and type II diabetes.

Among previously characterized mutants for the factors that can bind within Area I-II-III, the Hnf6-null mice (Jacquemin et al. 2003) exhibit delayed and reduced Pdx1 expression similar to that of $P d \times 1^{\Delta I-I I-I I I / \Delta I-I I-I I I}$ mutants. Although the pancreatic phenotype of $\mathrm{Hnf6}^{-{ }^{--}}$seems less severe overall, both types of mutant have delayed pancreas specification, impaired endocrine differentiation, and blocked ventral bud outgrowth. The phenotypic similarities raise the possibility that HNF6 may be a key regulator of $P d x 1$ via Area I-II-III during the early phases of pancreas formation. A future goal will be to test rigorously the contribution of individual trans-acting factors to the $P d \times 1^{\Delta I-I I-I I I / \Delta I-I I-I I I}$ phenotype by altering specific binding motifs in Area I-II-III.

\section{Materials and methods}

Pdx Area I-II-III flox mice

All animal experiments were performed in accordance with the guidelines of the Vanderbilt University Animal Care and Use Committee. Details of the targeting vector construction are available upon request from Y. Fujitani. In brief, a $5^{\prime}$-located 3.4-kb XbaI-PstI fragment (converted to a SalI-ClaI fragment; 5' arm), a 1.2-kb PCR fragment with added HindIII ends encompassing Area I-II-III, and an $\sim 10-\mathrm{kb}$ fragment encompassing the $P d \times 1$ gene from a NotI site added by PCR immediately $3^{\prime}$ of Area III to the SacI site $\sim 3 \mathrm{~kb} 3^{\prime}$ of the stop codon ( $\left.3^{\prime} \mathrm{arm}\right)$ were subcloned into pFRT.loxP (vector from M.A. Magnuson), which contains a thymidine kinase cassette, FRT-flanked neomycin resistance cassette, and loxP-flanked multiple cloning site. Linearized targeting vector was electroporated into ES cells (TL1/ 129S6 strain) and clones selected for homologous integration. Southern analysis of BamHI-digested DNA from doubly resistant ES cell clones revealed a targeting rate of $5.5 \%(10 / 182$ clones). ES cells were injected into C57BL/6 blastocysts that were transferred into pseudopregnant ICR female mice; male chimeras were bred to Black Swiss females and agouti offspring genotyped by Southern analysis. Heterozygous offspring were bred to ACTB:FLPe mice (see below) to remove the neomycinresistance cassette.

\section{Other genetically engineered animals}

EIIA-cre (H. Westphal, National Institutes of Health, Bethesda, MD) and ACTB:FLPe mice (S.M. Dymecki, Harvard Medical 
School, Boston, MA) were provided by B. Hogan (Duke University, Durham, NC). Pdx lacZko and $P t f 1 a^{\mathrm{CRE} /+}$ mice were described (Offield et al. 1996; Kawaguchi et al. 2002). All mice were kept on a C57BL/6 and DBA mixed-inbred background. Genotyping was by PCR or Southern blot with tail DNA from animals staged E16.5 through adult. DNA for genotyping was isolated from heads of E14.5 or earlier embryos. Primer sequences for PCR genotyping are available upon request to Y. Fujitani.

\section{$X$-gal staining}

Embryos or dissected tissues were fixed (ice-cold $4 \%$ paraformaldehyde/PBS, $4^{\circ} \mathrm{C}, 60 \mathrm{~min}$ ) then washed twice in permeabilization solution $(2 \mathrm{mM} \mathrm{MgCl}, 0.01 \%$ sodium deoxycholate, $0.02 \%$ Nonidet P-40 in PBS). $\beta$-Galactosidase was detected using X-gal (Wu et al. 1997). Samples were post-fixed and dehydrated for embedding as described below. Photographs were taken on an SZX12 microscope (Olympus) and Spot digital camera.

\section{Histology}

Dissected tissues were fixed (ice-cold $4 \%$ paraformaldehyde, $\left.4^{\circ} \mathrm{C}, 60 \mathrm{~min}\right)$, dehydrated in an ethanol series, washed into Histo-Clear (National Diagnostics), infiltrated in Histo-Clear/ paraffin $(1: 1 \mathrm{v} / \mathrm{v})$ and two changes of paraffin under vacuum at $56^{\circ} \mathrm{C}$, embedded, and cut into 5 - $\mu \mathrm{m}$ sections.

\section{Immunohistochemistry and confocal image analysis}

Hematoxylin-eosin (H\&E) staining and periodic acid-Schiff staining were as described (Offield et al. 1996). For immunoperoxidase, Vectastain ABC kit (Vector Labs) was used. Primary antibodies: guinea pig anti-bovine insulin (Linco), 1:10,000; anti-glucagon (Linco), 1:10,000; rabbit anti-somatostatin (Dako), 1:1000; guinea pig anti-pancreatic polypeptide (Linco), 1:2000; rabbit anti-amylase (Sigma), 1:20,000; rabbit anti-Pdx1 (Peshavaria et al. 1994; Kawaguchi et al. 2002), 1:5000. Antibodies for immunofluorescence: guinea pig anti-Pdx1 (Hingorani et al. 2003), 1:5000; rabbit anti-Pdx1, 1:250; rabbit anti-rat Glut2 (Alpha Diagnostic), 1:200. Secondary antibodies: CY2-conjugated donkey anti-guinea pig IgG (Jackson ImmunoReaerch laboratories, for insulin), CY3-conjugated donkey anti-rabbit IgG (for glucagon and Glut2) and CY5-conjugated anti-guinea pig IgG (Pdx1 staining in Fig. 2). Some samples were counterstained with the nuclear dye, YO-PRO-1 (Molecular Probes; 1: 1000 in PBS). Immunofluorescence was imaged on a Zeiss LSM 510 confocal microscope. TIFF images were processed in Adobe Photoshop.

\section{Quantification of gastrin-, GIP-, and serotonin-positive cells}

E18.5 foregut sections were immunostained with rabbit GIP antiserum (Research Diagnostics) or mouse serotonin monoclonal antibody (Dako). P7 distal stomach was immunostained with rabbit gastrin antiserum (Research Diagnostics). Sections were subjected to immunoperoxidase staining and light hematoxylin counterstain to reveal nuclei and general morphology. For each animal, cell counting was performed on five nonadjacent longitudinal sections, to avoid double scoring, within an area bounded by a 2:1 ratio rectangle whose short side was similar to the gut diameter $(\sim 000 \mu \mathrm{m})$, short side adjacent to the pylorus. For $P d \times 1^{-/-}$mutants, the rectangle was shifted $\sim 0.3$ $\mathrm{mm}$ distal to the pylorus to avoid the abnormal cuboidal epithelium in the rostral duodenum. Eight fields (two rows of four nonoverlapping fields [340 $\mu \mathrm{m} \times 450 \mu \mathrm{m}$ ] running down each side of the rectangle, with the gut wall included at one edge) of each section were photographed (SPOT camera) and printed at $450 \times$ magnification to count gastrin-, GIP-, or serotonin-positive cells, and the total number of epithelial cells.

\section{Glucose tolerance tests (IP-GTT)}

Following a 16- to 18-h fast, baseline blood glucose levels (milligrams per deciliter) were measured in tail-vein blood by BD Logic glucose monitor (Becton Dickinson). Dextrose $(2 \mathrm{mg} / \mathrm{g}$ body weight) was injected intraperitoneally and blood glucose measured at 15, 30, 60, 90, and $120 \mathrm{~min}$ after injection. For simultaneous measurement of plasma insulin, blood was obtained via the saphenous vein.

\section{Radioimmunoassay}

Plasma insulin and glucagon were assayed by radioimmunoassay (RIA; Linco) according to the manufacturer's protocol. Pancreatic insulin and glucagon content was assessed by RIA in acid-ethanol extracts of whole pancreas.

\section{Islet morphometric analysis}

Relative endocrine area was measured using NIH Image 1.41 software. For each experimental group, 10-wk-old mice were used. There was no statistical difference in pancreas weight among these mice. A total of nine sections were prepared from three pancreata (three sections per mouse). Each section was separated enough to avoid double scoring the same islet. The complete tissue area over all three sections was determined and percentage represented by islet cells calculated.

\section{Statistics}

Data are expressed as mean \pm SE. A two-way ANOVA for repeated measures was used to analyze time course differences between groups. When significant changes were obtained over time, post hoc comparisons were made by paired $t$-test. Pairwise comparison for the number of enteroendocrine cells, blood glucose levels, plasma insulin and glucagon, pancreatic insulin and glucagon, and relative endocrine area was made by unpaired $t$-test. $P$ values $<0.05$ were considered statistically significant.

\section{Acknowledgments}

We thank A. Means, K. Gerrish, S. Samaras, D. Melton, G. Gu, and members of the Wright, Stein, and Magnuson labs for discussions, and P. Soriano for R26R mice. Support from the Transgenic Mouse/ES Cell Shared Resource, Cell Imaging Core, Sequencing Core, and Histology Core at Vanderbilt University is acknowledged. This work was funded in part by Research Fellowships of the Japan Society for the Promotion of Science and Juvenile Diabetes Research Foundation International (to Y.F.) and NIH Grant U19 DK 042502 (to C.V.E.W.).

\section{References}

Ahlgren, U., Pfaff, S.L., Jessell, T.M., Edlund, T., and Edlund, H. 1997. Independent requirement for ISL1 in formation of pancreatic mesenchyme and islet cells. Nature 385: 257-260.

Ahlgren, U., Jonsson, J., Jonsson, L., Simu, K., and Edlund, H. 1998. $\beta$-Cell-specific inactivation of the mouse $\operatorname{Ipf} 1 / \mathrm{Pdx} 1$ gene results in loss of the $\beta$-cell phenotype and maturity 
onset diabetes. Genes \& Dev. 12: 1763-1768.

Andersen, F.G., Heller, R.S., Petersen, H.V., Jensen, J., Madsen, O.D., and Serup, P. 1999. Pax6 and Cdx2/3 form a functional complex on the rat glucagon gene promoter G1-element. FEBS Lett. 445: 306-310.

Bell, G.I. and Polonsky, K.S. 2001. Diabetes mellitus and genetically programmed defects in $\beta$-cell function. Nature 414: 788-791.

Ben-Shushan, E., Marshak, S., Shoshkes, M., Cerasi, E., and Melloul, D. 2001. A pancreatic $\beta$-cell-specific enhancer in the human PDX-1 gene is regulated by hepatocyte nuclear factor $3 \beta$ (HNF-3 $\beta$ ), HNF- $1 \alpha$, and SPs transcription factors. J. Biol. Chem. 276: 17533-17540.

Brissova, M., Shiota, M., Nicholson, W.E., Gannon, M., Knobel, S.M., Piston, D.W., Wright, C.V., and Powers, A.C. 2002. Reduction in pancreatic transcription factor PDX-1 impairs glucose-stimulated insulin secretion. I. Biol. Chem. 277: 11225-11232.

Caton, D., Calabrese, A., Mas, C., Serre-Beinier, V., Wonkam, A., and Meda, P. 2002. $\beta$-cell crosstalk: A further dimension in the stimulus-secretion coupling of glucose-induced insulin release. Diabetes Metab. 28: 3S45-3S53; discussion 3S108-3S112.

Dutta, S., Bonner-Weir, S., Montminy, M., and Wright, C. 1998. Regulatory factor linked to late-onset diabetes? Nature 392: 560 .

Gannon, M., Ray, M.K., Van Zee, K., Rausa, F., Costa, R.H., and Wright, C.V. 2000. Persistent expression of HNF6 in islet endocrine cells causes disrupted islet architecture and loss of $\beta$ cell function. Development 127: 2883-2895.

Gannon, M., Gamer, L.W., and Wright, C.V. 2001. Regulatory regions driving developmental and tissue-specific expression of the essential pancreatic gene pdx1. Dev. Biol. 238: 185201.

Gerrish, K., Gannon, M., Shih, D., Henderson, E., Stoffel, M., Wright, C.V., and Stein, R. 2000. Pancreatic $\beta$ cell-specific transcription of the pdx-1 gene. The role of conserved upstream control regions and their hepatic nuclear factor $3 \beta$ sites. J. Biol. Chem. 275: 3485-3492.

Gerrish, K., Cissell, M.A., and Stein, R. 2001. The role of hepatic nuclear factor $1 \alpha$ and PDX-1 in transcriptional regulation of the pdx-1 gene. J. Biol. Chem. 276: 47775-47784.

Gerrish, K., Van Velkinburg, J.C., and Stein, R. 2004. Conserved transcriptional regulatory domains of the pdx-1 gene. Mol. Endocrinol. 18: 533-548.

Gu, G., Dubauskaite, J., and Melton, D.A. 2002. Direct evidence for the pancreatic lineage: $\mathrm{NGN}^{+}$cells are islet progenitors and are distinct from duct progenitors. Development 129: $2447-2457$.

Guillam, M.T., Hummler, E., Schaerer, E., Yeh, J.I., Birnbaum, M.J., Beermann, F., Schmidt, A., Deriaz, N., and Thorens, B. 1997. Early diabetes and abnormal postnatal pancreatic islet development in mice lacking Glut-2. Nat. Genet. 17: 327-330.

Guz, Y., Montminy, M.R., Stein, R., Leonard, J., Gamer, L.W., Wright, C.V., and Teitelman, G. 1995. Expression of murine STF-1, a putative insulin gene transcription factor, in $\beta$ cells of pancreas, duodenal epithelium and pancreatic exocrine and endocrine progenitors during ontogeny. Development 121: $11-18$.

Harrison, K.A., Thaler, J., Pfaff, S.L., Gu, H., and Kehrl, J.H. 1999. Pancreas dorsal lobe agenesis and abnormal islets of Langerhans in Hlxb9-deficient mice. Nat. Genet. 23: 71-75.

Hebrok, M., Kim, S.K., and Melton, D.A. 1998. Notochord repression of endodermal Sonic hedgehog permits pancreas development. Genes \& Dev. 12: 1705-1713.

Hingorani, S.R., Petricoin, E.F., Maitra, A., Rajapakse, V., King,
C., Jacobetz, M.A., Ross, S., Conrads, T.P., Veenstra, T.D., Hitt, B.A., et al. 2003. Preinvasive and invasive ductal pancreatic cancer and its early detection in the mouse. Cancer Cell 4: 437-450.

Holland, A.M., Hale, M.A., Kagami, H., Hammer, R.E., and MacDonald, R.J. 2002. Experimental control of pancreatic development and maintenance. Proc. Natl. Acad. Sci. 99: $12236-12241$.

Jacquemin, P., Lemaigre, F.P., and Rousseau, G.G. 2003. The Onecut transcription factor HNF-6 (OC-1) is required for timely specification of the pancreas and acts upstream of Pdx-1 in the specification cascade. Dev. Biol. 258: 105-116.

Jenny, M., Uhl, C., Roche, C., Duluc, I., Guillermin, V., Guillemot, F., Jensen, J., Kedinger, M., and Gradwohl, G. 2002. Neurogenin 3 is differentially required for endocrine cell fate specification in the intestinal and gastric epithelium. EMBO J. 21: 6338-6347.

Jensen, J. 2004. Gene regulatory factors in pancreatic development. Dev. Dyn. 229: 176-200.

Jepeal, L.I., Fujitani, Y., Boylan, M.O., Wilson, C.N., Wright, C.V., and Wolfe, M.M. 2005. Cell-specific expression of glucose-dependent-insulinotropic polypeptide is regulated by the transcription factor PDX-1. Endocrinology 146: 383-391.

Johnson, J.D., Ahmed, N.T., Luciani, D.S., Han, Z., Tran, H., Fujita, J., Misler, S., Edlund, H., and Polonsky, K.S. 2003. Increased islet apoptosis in $\mathrm{Pdx}^{+/-}$mice. J. Clin. Invest. 111: $1147-1160$.

Jonsson, J., Carlsson, L., Edlund, T., and Edlund, H. 1994. Insulin-promoter-factor 1 is required for pancreas development in mice. Nature 371: 606-609.

Kawaguchi, Y., Cooper, B., Gannon, M., Ray, M., MacDonald, R.J., and Wright, C.V. 2002. The role of the transcriptional regulator Ptfla in converting intestinal to pancreatic progenitors. Nat. Genet. 32: 128-134.

Kim, S.K. and Hebrok, M. 2001. Intercellular signals regulating pancreas development and function. Genes \& Dev. 15: 111127.

Kim, S.K., Hebrok, M., and Melton, D.A. 1997. Notochord to endoderm signaling is required for pancreas development. Development 124: 4243-4252.

Kubo, A., Shinozaki, K., Shannon, J.M., Kouskoff, V., Kennedy, M., Woo, S., Fehling, H.J., and Keller, G. 2004. Development of definitive endoderm from embryonic stem cells in culture. Development 131: 1651-1662.

Lammert, E., Cleaver, O., and Melton, D. 2001. Induction of pancreatic differentiation by signals from blood vessels. Science 294: 564-567.

Larsson, L.I. 2000. Developmental biology of gastrin and somatostatin cells in the antropyloric mucosa of the stomach. Microsc. Res. Tech. 48: 272-281.

Larsson, L.I., Madsen, O.D., Serup, P., Jonsson, J., and Edlund, H. 1996. Pancreatic-duodenal homeobox 1-role in gastric endocrine patterning. Mech. Dev. 60: 175-184.

Larsson, L.I., St-Onge, L., Hougaard, D.M., Sosa-Pineda, B., and Gruss, P. 1998. Pax 4 and 6 regulate gastrointestinal endocrine cell development. Mech. Dev. 79: 153-159.

Lee, C.S., Perreault, N., Brestelli, J.E., and Kaestner, K.H. 2002. Neurogenin 3 is essential for the proper specification of gastric enteroendocrine cells and the maintenance of gastric epithelial cell identity. Genes \& Dev. 16: 1488-1497.

Leonard, J., Peers, B., Johnson, T., Ferreri, K., Lee, S., and Montminy, M.R. 1993. Characterization of somatostatin transactivating factor-1, a novel homeobox factor that stimulates somatostatin expression in pancreatic islet cells. Mol. Endocrinol. 7: 1275-1283.

Li, H., Arber, S., Jessell, T.M., and Edlund, H. 1999. Selective 
agenesis of the dorsal pancreas in mice lacking homeobox gene Hlxb9. Nat. Genet. 23: 67-70.

Marshak, S., Benshushan, E., Shoshkes, M., Havin, L., Cerasi, E., and Melloul, D. 2000. Functional conservation of regulatory elements in the pdx-1 gene: PDX-1 and hepatocyte nuclear factor $3 \beta$ transcription factors mediate $\beta$-cell-specific expression. Mol. Cell. Biol. 20: 7583-7590.

Melloul, D., Marshak, S., and Cerasi, E. 2002. Regulation of pdx-1 gene expression. Diabetes 51: S320-S325.

Miller, C.P., McGehee Jr., R.E., and Habener, J.F. 1994. IDX-1: A new homeodomain transcription factor expressed in rat pancreatic islets and duodenum that transactivates the somatostatin gene. EMBO J. 13: 1145-1156.

Naya, F.J., Huang, H.P., Qiu, Y., Mutoh, H., DeMayo, F.J., Leiter, A.B., and Tsai, M.J. 1997. Diabetes, defective pancreatic morphogenesis, and abnormal enteroendocrine differentiation in BETA2/NeuroD-deficient mice. Genes \& Dev. 11: 2323-2334.

Offield, M.F., Jetton, T.L., Labosky, P.A., Ray, M., Stein, R.W., Magnuson, M.A., Hogan, B.L. and Wright, C.V. 1996. PDX-1 is required for pancreatic outgrowth and differentiation of the rostral duodenum. Development 122: 983-995.

Ohlsson, H., Karlsson, K., and Edlund, T. 1993. IPF1, a homeodomain-containing transactivator of the insulin gene. EMBO J. 12: 4251-4259.

Peshavaria, M., Gamer, L., Henderson, E., Teitelman, G., Wright, C.V., and Stein, R. 1994. XIHbox 8, an endodermspecific Xenopus homeodomain protein, is closely related to a mammalian insulin gene transcription factor. Mol. Endocrinol. 8: 806-816.

Rosanas-Urgell, A., Marfany, G., and Garcia-Fernandez, J. 2005. Pdx1-related homeodomain transcription factors are distinctly expressed in mouse adult pancreatic islets. Mol. Cell. Endocrinol. 237: 59-66.

Samaras, S.E., Cissell, M.A., Gerrish, K., Wright, C.V., Gannon, M., and Stein, R. 2002. Conserved sequences in a tissuespecific regulatory region of the pdx-1 gene mediate transcription in pancreatic $\beta$ cells: Role for hepatocyte nuclear factor $3 \beta$ and Pax6. Mol. Cell. Biol. 22: 4702-4713.

Samaras, S.E., Zhao, L., Means, A., Henderson, E., Matsuoka, T.A., and Stein, R. 2003. The islet $\beta$ cell-enriched RIPE3b1/ Maf transcription factor regulates pdx-1 expression. J. Biol. Chem. 278: 12263-12270.

Servitja, J.M. and Ferrer, J. 2004. Transcriptional networks controlling pancreatic development and $\beta$ cell function. Diabetologia 47: 597-613.

Sharma, S., Jhala, U.S., Johnson, T., Ferreri, K., Leonard, J., and Montminy, M. 1997. Hormonal regulation of an islet-specific enhancer in the pancreatic homeobox gene STF-1. Mol. Cell. Biol. 17: 2598-2604.

Shih, D.Q., Heimesaat, M., Kuwajima, S., Stein, R., Wright, C.V., and Stoffel, M. 2002. Profound defects in pancreatic $\beta$-cell function in mice with combined heterozygous mutations in Pdx-1, Hnf-1 $\alpha$, and Hnf-3 $\beta$. Proc. Natl. Acad. Sci. 99: 3818-3823.

Stoffers, D.A., Zinkin, N.T., Stanojevic, V., Clarke, W.L., and Habener, J.F. 1997. Pancreatic agenesis attributable to a single nucleotide deletion in the human IPF1 gene coding sequence. Nat. Genet. 15: 106-110.

Stoffers, D.A., Stanojevic, V., and Habener, J.F. 1998. Insulin promoter factor- 1 gene mutation linked to early-onset type 2 diabetes mellitus directs expression of a dominant negative isoprotein. J. Clin. Invest. 102: 232-241.

Tada, S., Era, T., Furusawa, C., Sakurai, H., Nishikawa, S., Kinoshita, M., Nakao, K., and Chiba, T. 2005. Characterization of mesendoderm: A diverging point of the definitive endo- derm and mesoderm in embryonic stem cell differentiation culture. Development 132: 4363-4374.

Thorens, B. 2001. GLUT2 in pancreatic and extra-pancreatic gluco-detection (review). Mol. Membr. Biol. 18: 265-273.

Van Velkinburgh, J.C., Samaras, S.E., Gerrish, K., Artner, I., and Stein, R. 2005. Interactions between areas I and II direct pdx-1 expression specifically to islet cell types of the mature and developing pancreas. J. Biol. Chem. 280: 38438-38444.

Waeber, G., Thompson, N., Nicod, P., and Bonny, C. 1996. Transcriptional activation of the GLUT2 gene by the IPF-1/ STF-1/IDX-1 homeobox factor. Mol. Endocrinol. 10: 13271334.

Watada, H., Kajimoto, Y., Umayahara, Y., Matsuoka, T., Kaneto, H., Fujitani, Y., Kamada, T., Kawamori, R., and Yamasaki, Y. 1996. The human glucokinase gene $\beta$-cell-type promoter: An essential role of insulin promoter factor 1/PDX-1 in its activation in HIT-T15 cells. Diabetes 45: $1478-1488$.

Wilson, M.E., Scheel, D., and German, M.S. 2003. Gene expression cascades in pancreatic development. Mech. Dev. 120: $65-80$.

Wright, C.V., Schnegelsberg, P., and De Robertis, E.M. 1989. XlHbox 8: A novel Xenopus homeo protein restricted to a narrow band of endoderm. Development 105: 787-794.

Wu, K.L., Gannon, M., Peshavaria, M., Offield, M.F., Henderson, E., Ray, M., Marks, A., Gamer, L.W., Wright, C.V., and Stein, R. 1997. Hepatocyte nuclear factor $3 \beta$ is involved in pancreatic $\beta$-cell-specific transcription of the pdx-1 gene. Mol. Cell. Biol. 17: 6002-6013.

Yamagata, K., Nammo, T., Moriwaki, M., Ihara, A., Iizuka, K., Yang, Q., Satoh, T., Li, M., Uenaka, R., Okita, K., et al. 2002. Overexpression of dominant-negative mutant hepatocyte nuclear factor- $1 \alpha$ in pancreatic $\beta$-cells causes abnormal islet architecture with decreased expression of E-cadherin, reduced $\beta$-cell proliferation, and diabetes. Diabetes 51: 114123.

Yoshitomi, H. and Zaret, K.S. 2004. Endothelial cell interactions initiate dorsal pancreas development by selectively inducing the transcription factor Ptfla. Development 131: $807-817$. 


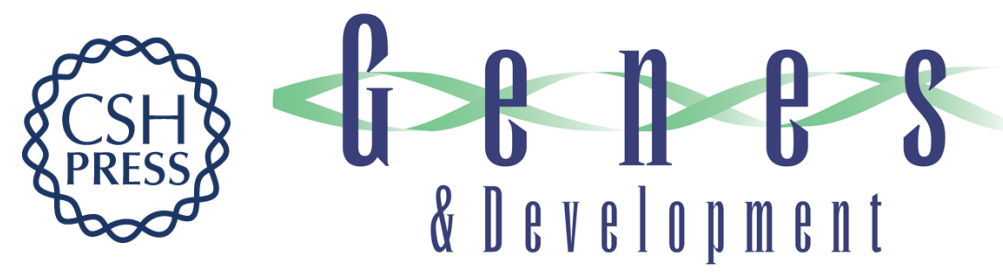

\section{Targeted deletion of a cis-regulatory region reveals differential gene dosage requirements for $\boldsymbol{P d x 1}$ in foregut organ differentiation and pancreas formation}

Yoshio Fujitani, Shuko Fujitani, Daniel F. Boyer, et al.

Genes Dev. 2006, 20:

Access the most recent version at doi:10.1101/gad.1360106

Supplemental Material

References License

Email Alerting Service
http://genesdev.cshlp.org/content/suppl/2006/01/18/20.2.253.DC1

This article cites 62 articles, 30 of which can be accessed free at: http://genesdev.cshlp.org/content/20/2/253.full.html\#ref-list-1

Receive free email alerts when new articles cite this article - sign up in the box at the top right corner of the article or click here.

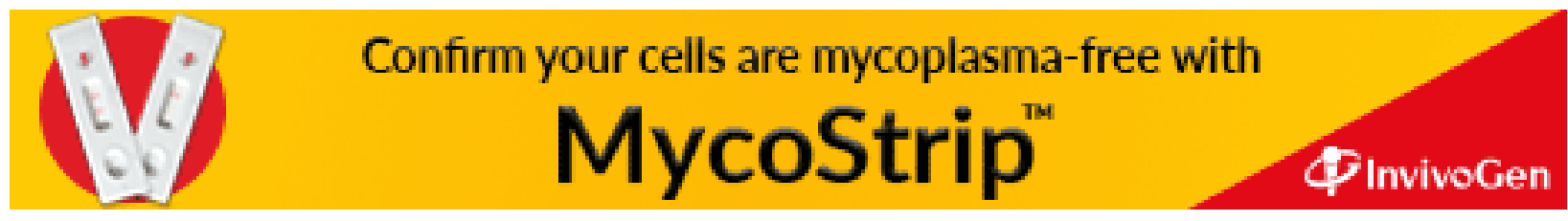

